\title{
Can an Earth System Model simulate better climate change at mid-Holocene than an AOGCM? A comparison study of MIROC-ESM and MIROC3
}

\author{
R. Ohgaito ${ }^{1}$, T. Sueyoshi ${ }^{1}$, A. Abe-Ouchi ${ }^{1,2}$, T. Hajima ${ }^{1}$, S. Watanabe ${ }^{1}$, H.-J. Kim ${ }^{1}$, A. Yamamoto ${ }^{2}$, and M. Kawamiya ${ }^{1}$ \\ ${ }^{1}$ Japan Agency for Marine-Earth Science and Technology, 3173-25, Showa-machi, Kanazawa-ward, \\ Yokohama, 236-0001, Japan \\ ${ }^{2}$ Atmosphere and Ocean Research Institute, The University of Tokyo, 5-1-5, Kashiwanoha, Kashiwa-shi, \\ Chiba, 277-8564, Japan \\ Correspondence to: R. Ohgaito (ohgaito@jamstec.go.jp)
}

Received: 30 July 2012 - Published in Clim. Past Discuss.: 9 August 2012

Revised: 12 June 2013 - Accepted: 19 June 2013 - Published: 19 July 2013

\begin{abstract}
The importance of evaluating models through paleoclimate simulations is becoming more recognized in efforts to improve climate projection. To evaluate an integrated Earth System Model, MIROC-ESM, we performed simulations in time-slice experiments for the mid-Holocene (6000 $\mathrm{yr}$ before present, $6 \mathrm{ka}$ ) and preindustrial (1850 AD, $0 \mathrm{ka})$ periods under the protocol of the Coupled Model Intercomparison Project 5/Paleoclimate Modelling Intercomparison Project 3. We first give an overview of the simulated global climates by comparing with simulations using a previous version of the MIROC model (MIROC3), which is an atmosphere-ocean coupled general circulation model. We then comprehensively discuss various aspects of climate change with $6 \mathrm{ka}$ forcing and how the differences in the models can affect the results. We also discuss the representation of the precipitation enhancement at $6 \mathrm{ka}$ over northern Africa. The precipitation enhancement at $6 \mathrm{ka}$ over northern Africa according to MIROC-ESM does not differ greatly from that obtained with MIROC3, which means that newly developed components such as dynamic vegetation and improvements in the atmospheric processes do not have significant impacts on the representation of the $6 \mathrm{ka}$ monsoon change suggested by proxy records. Although there is no drastic difference between the African monsoon representations of the two models, there are small but significant differences in the precipitation enhancement over the Sahara in early summer, which can be related to the representation of the sea surface temperature rather than the vegetation coupling in MIROC-ESM.
\end{abstract}

Because the oceanic parts of the two models are identical, the difference in the sea surface temperature change is ultimately attributed to the difference in the atmospheric and/or land modules, and possibly the difference in the representation of low-level clouds.

\section{Introduction}

In efforts to improve climate projection, the importance of evaluating climate models through paleoclimate simulations is being increasingly recognized by the Intergovernmental Panel on Climate Change (IPCC). The Coupled Model Intercomparison Project phase 5 (CMIP5) (Taylor et al., 2009) and Paleoclimate Modelling Intercomparison Project phase 3 (PMIP3) are initiatives for the evaluation of models endorsed by the World Climate Research Programme and the International Geosphere-Biosphere Programme.

CMIP5/PMIP3 proposes several coordinated paleoclimate simulations to evaluate the different model outputs against paleoproxy records (Braconnot et al., 2012). The midHolocene ( $6000 \mathrm{yr}$ before present; hereafter, $6 \mathrm{ka}$ ) has been chosen as a benchmarking period. The period $6 \mathrm{ka}$ is characterized by enhanced seasonality in the Northern Hemisphere and reduced seasonality in the Southern Hemisphere due to a difference in solar insolation compared with the present-day, associated with orbital variations of the Earth (Berger, 1978). Many proxy records such as pollen (Prentice et al., 2000; 
Harrison et al., 2001; Bigelow et al., 2003; Pickett et al., 2004; Wohlfahrt et al., 2008; Bartlein et al., 2011) and lake level (Kohfeld and Harrison, 2000; Yu et al., 2000; Harrison et al., 2003; Lezine et al., 2011) suggest humid and vegetated conditions over the Sahara, and a northward shift of vegetation in the northern high latitudes.

Paleoclimate Modelling Intercomparison Project phase 1 (PMIP1) compared simulations using atmospheric general circulation models (AGCMs). Joussaume et al. (1999) reported that the seasonal cycle of temperature over land is enhanced in the Northern Hemisphere at $6 \mathrm{ka}$. The resulting increase in land-sea temperature contrast enhances lowlevel convergence into the monsoon low over the continents. Therefore the position of the monsoonal precipitation is also affected and an enhancement and northward shift of the summer African and Indian monsoons are seen. The modeled climate changes were consistent in sign with the paleoclimate proxy records, but failed to simulate an increase in precipitation sufficient to maintain a widely vegetated Sahara.

Using an intermediate complexity model, Ganopolski et al. (1998) found that vegetation played a role in the increase in subtropical precipitation at $6 \mathrm{ka}$. There have been several attempts to simulate vegetation and/or ocean feedback using an asynchronous coupling scheme and reported a somewhat northward shift of vegetation in the Sahara (Texier et al., 1997; Claussen and Gayler, 1997). Braconnot et al. (1999) coupled vegetation (diagnoses) and an oceanic general circulation model (OGCM) asynchronously to an AGCM and concluded that both contribute to an enhancement of the African precipitation. An alternative way to test the vegetation feedback on monsoon activity around $6 \mathrm{ka}$ is to simulate the situation at that time using boundary conditions derived from the vegetation type reconstructed from pollen proxy records (Kutzbach et al., 1996b; Brostrom et al., 1998; Knorr and Schnitzler, 2006). Such studies also reported that paleovegetation provides a positive feedback to the monsoon, but the precipitation enhancement is insufficient to maintain vegetation. Full coupling of the different climatic components was first implemented around the beginning of the 21 st century. A study employing atmosphere-vegetation coupling revealed more grassland at the desert border (Doherty et al., 2000). Levis et al. (2004) carried out atmosphere-ocean-vegetation coupled simulations and concluded that the albedo change is important for increased precipitation. Recently Vamborg et al. (2011) tested a dynamic albedo scheme in a GCM and found that detailed treatment of albedo helps to enhance precipitation over the Sahel region in a $6 \mathrm{ka}$ experiment. These studies suggested some consistency with an early pioneering study by Charney (1975), which proposed that the albedo of the desert surface is higher than that of the vegetated surface and this enhances the sinking motion of the atmosphere. Although many attempts had been carried out to investigate precipitation-vegetation feedback over the Sahara, vegetation coverage is mostly limited to the desert border and none of the models simulated a "Green Sahara", a condition suggested by the proxy records. Although one model indicated negative vegetation-precipitation feedback (Notaro et al., 2008; Wang et al., 2008), it has been reported that the feedback is dependent on the vegetation type (Liu et al., 2010).

In addition to the low-latitude changes, Kutzbach et al. (1996a) compared models with and without albedo feedback, and suggested that the lowering of albedo at the northern high latitudes, associated with the expansion of vegetation, facilitates the northward expansion of vegetation. Although Otto et al. (2009) reported that the contribution of vegetation to warming at northern high latitudes is small compared with the contributions of the atmosphere and ocean, O'ishi and Abe-Ouchi (2011) claimed that a dynamic vegetation model provided a larger positive feedback on climate temperature changes at 6 ka over Siberia.

We now consider studies reporting the role of the ocean in the African and Asian monsoons. Hewitt and Mitchell (1998) compared experimental results obtained by using an atmosphere-ocean coupled general circulation model (AOGCM) and an AGCM under 6 ka insolation forcing, and reported that the ocean coupling enhanced precipitation over Africa, India, and the Indian Ocean. Braconnot et al. (2000) reported that the African and Asian monsoons were enhanced with ocean coupling. On the other hand, Voss and Mikolajewicz (2001) reported that monsoon enhancement was suppressed with ocean coupling in Asia. Their results were based on long-term integrations of AGCM simulations periodically coupled with an OGCM. Also using asynchronous coupling of an AGCM and OGCM, Liu et al. (1999) reported that the Asian monsoon was attenuated with ocean coupling according to analyses of the monsoon response to $11 \mathrm{ka}$ orbital forcing. Liu et al. (2003) carried out AOGCM simulations for several Holocene time slices and found that ocean coupling attenuated the Asian monsoon enhancement. Dallmeyer et al. (2010) used an Earth system model (ESM) and investigated the effect of vegetation and ocean components on the total change in the Asian monsoon at $6 \mathrm{ka}$. They found that the ocean played a major role in the further enhancement of the monsoon activity compared to the vegetation feedback.

Zhao et al. (2005, 2007) and Zhao and Harrison (2012) made a multimodel intercomparison and reported that the sea surface temperature (SST) pattern played a role in the enhancement of the African monsoon. Ohgaito and AbeOuchi (2007) reported that ocean thermodynamics played a major role in the further enhancement of the African monsoon and attenuation of the Asian monsoon compared to the ocean dynamics. Consistent results were reported by Marzin and Braconnot (2009a,b). Ohgaito and Abe-Ouchi (2009) reported on the importance of the present-day SST reproduction to Asian monsoon enhancements at $6 \mathrm{ka}$.

Not only does the ocean affect the monsoons but the monsoon changes can also influence oceanic variability. Weaker amplitude of El Niño/Southern Oscillation (ENSO) at $6 \mathrm{ka}$ 
is known from paleo-proxy records (Rodbell et al., 1999; Tudhope et al., 2001; McGregor and Gagan, 2004; Gagan et al., 2004). Liu et al. (2000) proposed that the intensified Asian monsoon increases the Pacific trade wind through the Walker circulation which then intensifies the equatorial upwelling. The cooling of the equatorial SSTs in the growing season of El Niño can damp its growth.

Although the present study focuses on climate and monsoon changes at $6 \mathrm{ka}$, an understanding of the mechanisms responsible for the present-day monsoon variability may be useful in investigating the response of the monsoon to climate change. We briefly look at the various influences that have been reported in studies on the strength of the modern African monsoon. Many studies on the variability of presentday Sahel precipitation suggest a correlation with the ocean. Ocean forcing is the dominant driver of the decadal West African monsoon variability (Biasutti et al., 2008). The influence of the SST variability on the African monsoon has been intensively investigated as part of the African Monsoon Multidisciplinary Analyses project. The SST in each basin, such as the Mediterranean Sea, Indian Ocean, and Atlantic Ocean, affects the inter-annual variability of the monsoon, whereas the global pattern affects the decadal variability (Rodriguez-Fonseca et al., 2011; Mohino et al., 2011; Losada et al., 2010a,b). Fontaine et al. (2010) suggested that anomalously high Mediterranean SST leads to a strong West African monsoon. On the other hand, Bader and Latif (2003) suggested that anomalously high Indian Ocean SST correlates to less Sahel precipitation. Vizy and Cook (2001) stated that the SST over the Gulf of Guinea and eastern North Atlantic affects the African monsoon.

There are many studies on the present-day soil moisturemonsoon feedback (Xue et al., 2004; Douville et al., 2001, 2007; Bergengren et al., 2001; Philippon et al., 2005) suggesting that the enhanced soil moisture favours a stronger monsoon. There have been few studies on the presentday vegetation-monsoon feedback, but Zeng et al. (1999) claimed that the Sahel rainfall variability is influenced by SST variations and that the vegetation feedback is found to increase this variability for longer timescales such as interdecadal. Notaro et al. (2011) investigated the vegetation feedback for the sub-annual climate by reducing the vegetation cover and concluded that the reduction in vegetation cover influences the damping of monsoon activity. To understand the mechanisms responsible for monsoon changes under climate change, it is necessary to consider the roles played by these factors.

Besides discussing precipitation variation and its causes, we will also consider the global monsoon rainfall, which is an essential feature of the seasonal contrast in the Earth's hydrological cycle. Wang et al. (2012) proposed the idea of global monsoon and defined the global monsoon domain as the regions where the local summer-minus-winter precipitation rate exceeds $2.0 \mathrm{~mm} \mathrm{day}^{-1}$ and the local summer precipitation exceeds $55 \%$ of the annual total. The concept of global monsoon has proven to be a useful tool in delineating the global monsoon system as a whole, investigating the trend and inter-annual variability of the global water cycle, and examining numerical model fidelity (Kim et al., 2011; Wang et al., 2011). This will be applied to the evaluation of the monsoon changes at $6 \mathrm{ka}$ in Sect. 5.

For future climate projection and for climate change studies, the importance of the carbon cycle in the environment has been recognized in IPCC reports. The MIROC team has developed an ESM, namely MIROC-ESM (Watanabe et al., 2011). The newly developed model should be tested against various conditions to instill confidence in its climate projection. Paleoclimate experiments provide a unique opportunity for such testing. To evaluate MIROC-ESM, we performed simulations in time-slice experiments for $6 \mathrm{ka}$ (corresponding to mid-Holocene (exp3.4) in the CMIP5 database) and $0 \mathrm{ka}$ (corresponding to piControl (exp3.1) in the CMIP5 database) under the CMIP5/PMIP3 protocol as described by Sueyoshi et al. (2013).

In this study, we give an overview of the climate changes simulated by using MIROC-ESM under $6 \mathrm{ka}$ forcing. Furthermore, we focus on African monsoon activity at $6 \mathrm{ka}$. We present various analyses in which the MIROC-ESM results for African precipitation are compared with results obtained with MIROC3, which is a previous MIROC AOGCM, and discuss possible factors affecting the representation of monsoon changes at $6 \mathrm{ka}$. It is useful to compare the two similar models MIROC-ESM and MIROC3, for which we know the difference in components, and discussing the consistency and differences in the represented climate change in order to explore the source of the difference in climate change simulations.

This article is organized as follows. Firstly, we explain the model and experimental setup in Sect. 2. The 0 ka climate representation is then shown in Sect. 3. The global changes at $6 \mathrm{ka}$ are explained in Sect. 4, followed by analyses of monsoon changes at $6 \mathrm{ka}$ in Sect. 5. Finally, we conclude the study in Sect. 6.

\section{Models and experimental setup}

\subsection{Model description}

We use three models in this study, namely the ESM, MIROCESM and AOGCM MIROC3, and also the AGCM part of MIROC3 for additional sensitivity experiments. Because MIROC-ESM is based on MIROC3, we firstly explain MIROC3 briefly, and then the differences between MIROCESM and MIROC3.

MIROC3 is an AOGCM, more precisely called MIROC3.2 (medium resolution) (K-1 model developers, 2004) which was used in the IPCC Fourth Assessment Report (AR4). The AGCM part has a horizontal resolution of spectral T42, and 20 vertical layers (the top of the atmosphere is at $10 \mathrm{hPa}$ ) 
and is coupled with the land module, MATSIRO, in which the leaf area index (LAI) is prescribed. The biogeochemical cycle is not included. The vegetation types are prescribed to have modern distributions for the experiments in this study. The OGCM module has a resolution of about horizontal $1^{\circ}$ and 44 vertical layers. The model has a simplified aerosol transportation component, sSPRINTARS.

MIROC-ESM was developed from MIROC3 to better simulate future climate projections (Watanabe et al., 2011). It has, as one component, an AGCM with a horizontal atmospheric resolution of T42 and 80 vertical layers including the stratosphere. The atmosphere is coupled with the land module MATSIRO, and an OGCM part that is identical to that of MIROC3. MIROC-ESM has an aerosol transportation model, SPRINTARS (Takemura et al., 2000, 2002, 2005), a terrestrial ecosystem component called the Spatially Explicit Individual-Based Dynamic Global Vegetation Model (SEIBDGVM) (Sato et al., 2007), an ocean ecosystem component, and improved radiation code "mstrmX", which eliminates the cold bias (Sekiguchi and Nakajima, 2008) in MIROC3. The newly incorporated SEIB-DGVM calculates vegetation dynamics such as photosynthesis, respiration, growth, and mortality. There are 17 vegetation types as listed in Table 1 . This component predicts the LAI during the calculation. The above processes are computed using physical variables provided by MIROC-ESM. The diagnosed LAI is then used for the calculations of biogeophysical processes in MATSIRO: the processes for radiation transfer, including surface albedo, interception of precipitation, and energy transfer through latent and sensible heat. The carbon cycle is fully calculated for the atmosphere, land, and ocean. The two models are compared in Table 2. The model structure of MIROC-ESM was presented schematically by Sueyoshi et al. (2013). Additionally, several sensitivity experiments are performed using the AGCM part of MIROC3. Details are given in Sect. 2.2.

\subsection{Experimental setup}

We performed time-slice experiments for 6 and $0 \mathrm{ka}$ under the CMIP5/PMIP3 protocol. The major difference between 0 and 6 ka conditions was the Earth's orbit. Additionally, there was a small difference in the greenhouse gas levels. The other boundary conditions were the same. The orbital parameters for $6 \mathrm{ka}$ were set as follows: 0.018682 for eccentricity, $24.105^{\circ}$ for obliquity and $180.87^{\circ}$ for perihelion (Berger, 1978). As for the greenhouse gases, $\mathrm{CO}_{2}$, $\mathrm{N}_{2} \mathrm{O}$, and $\mathrm{CH}_{4}$ had $6 \mathrm{ka}$ concentrations of $280,0.27$, and $0.65 \mathrm{ppm}$, respectively. In the $0 \mathrm{ka}$ experiment, the orbital parameters were $0.0672,23.45^{\circ}$, and $102.04^{\circ}$ for the eccentricity, obliquity, and perihelion, respectively. Because the experiments using MIROC3 were performed before the formalization of CMIP5, there is a small difference between $0 \mathrm{ka}$ greenhouse gas levels for MIROC-ESM and MIROC3. $\mathrm{CO}_{2}$ and $\mathrm{N}_{2} \mathrm{O}$ levels are the same for both models (285 and $0.28 \mathrm{ppm}$, respectively) but $\mathrm{CH}_{4}$ levels are 0.79 and $0.86 \mathrm{ppm}$
Table 1. Vegetation types in SEIB-DGVM.

\begin{tabular}{ll}
\hline 1 & Polar desert \\
2 & Arctic/Alpine tundra \\
3 & Tropical rain forest (wet throughout the year) \\
4 & Tropical rain forest (precipitation with seasonality) \\
5 & Tropical deciduous forest \\
6 & Temperate coniferous forest \\
7 & Temperate broad-leaved evergreen forest \\
8 & Temperate deciduous forest \\
9 & Boreal evergreen forest/woodland \\
10 & Boreal deciduous forest/woodland \\
11 & Short grassland \\
12 & Tall grassland \\
13 & Moist savanna \\
14 & Dry savanna \\
15 & Xeric woodland/scrubland \\
16 & Arid shrubland/steppe \\
17 & Desert \\
\hline
\end{tabular}

for MIROC-ESM and MIROC3, respectively. The effect of this greenhouse gas difference is more than one order smaller than that of the difference in the forcing of 0 and $6 \mathrm{ka}$ (not shown).

The change in solar insolation (Fig. 1 in Ohgaito and Abe-Ouchi, 2007) suggests that seasonality was enhanced in the Northern Hemisphere and weakened in the Southern Hemisphere, especially at mid-latitudes during $6 \mathrm{ka}$. The annual net solar radiation increased at high latitudes and decreased in the tropics, compared with $0 \mathrm{ka}$.

In the MIROC-ESM simulation, the $0 \mathrm{ka}$ simulation consisted of a $629 \mathrm{yr}$ integration, while the $6 \mathrm{ka}$ simulation was initiated from the 250th year of the 0 ka simulation and consisted of a $379 \mathrm{yr}$ integration. In the MIROC 3 simulation, the $0 \mathrm{ka}$ experiment consisted of a $1050 \mathrm{yr}$ integration and the $6 \mathrm{ka}$ experiment a $650 \mathrm{yr}$ integration. In each of these four cases, the climatology of the last $100 \mathrm{yr}$ was used for analyses. These experiments are identical to those carried out by Ohgaito and Abe-Ouchi (2007) and submitted to PMIP phase 2 (PMIP2).

We performed additional sensitivity experiments using the AGCM part of MIROC3 to deepen our understanding of the precipitation changes over the Sahara at $6 \mathrm{ka}$. The reason for basing the tests on MIROC 3 is that MIROC-ESM has a computational cost one order of magnitude higher than that of MIROC3. The sensitivity experiments are listed in Table 3. M3Amiroc3 represents the set of experiments (0 and $6 \mathrm{ka})$ using the MIROC3 AGCM with prescribed SSTs. The SSTs are taken from the climatologies of the MIROC 3 experiments for 0 and $6 \mathrm{ka}$. M3Aesm is the same as M3Amiroc3 but with SSTs simulated in MIROC-ESM. M3Aesmofs is an additional $6 \mathrm{ka}$ experiment associated with M3Aesm. The SSTs in the $6 \mathrm{ka}$ experiment of M3Aesmofs are the climatological values as simulated by using MIROC-ESM but with the 
Table 2. Model comparison of MIROC-ESM and MIROC3.

\begin{tabular}{lll}
\hline Model name & MIROC-ESM & MIROC3 \\
\hline Reference & Watanabe et al. (2011) & K-1 Model developers (2004) \\
Model type & Earth System Model & AOGCM \\
Contribution to IPCC & Planned for Fifth & AR4 \\
& Assessment Report & (as miroc-medres) \\
Resolution of atmosphere & T42 80 layers & T42 20 layers \\
Resolution of ocean & $\sim 1^{\circ} 44$ layers & $\sim 1^{\circ} 44$ layers \\
Number of soil layers & 6 & 5 \\
Top level of the atmosphere & 0.003 hPa & $10 \mathrm{hPa}$ \\
Radiation & Updated version of MSTRN & MSTRN \\
Vegetation & SEIB-DGVM, MATSIRO & MATSIRO \\
Ocean carbon cycle & Yes & No \\
Aerosol & SPRINTARS & sSPRINTARS \\
\hline
\end{tabular}

(a) $0 \mathrm{ka}$ precipitation [mm/day]

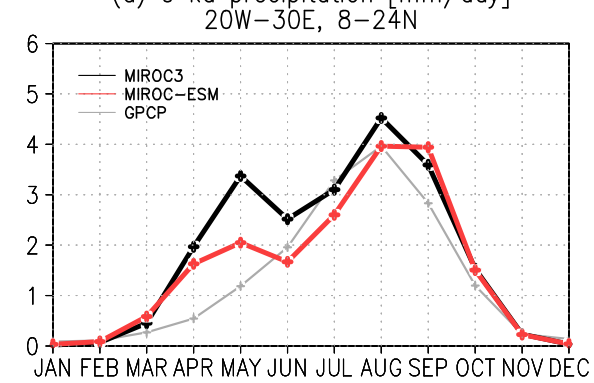

(c) precipitation change [\% of $\mathrm{Oka}]$

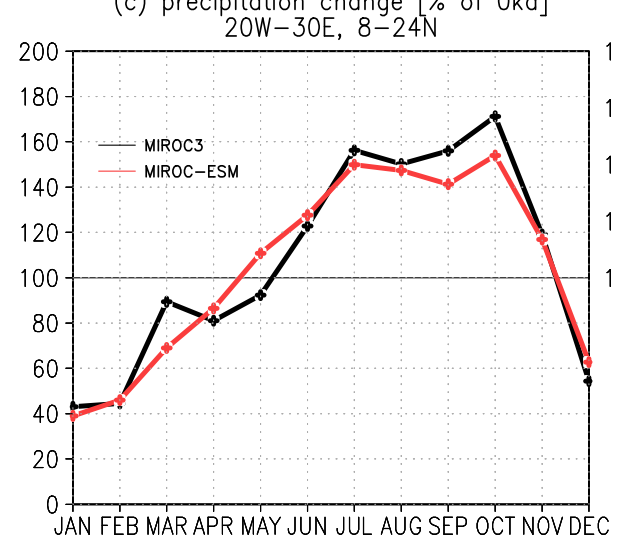

(b) $0 \mathrm{ka}$ precipitation [mm/day]

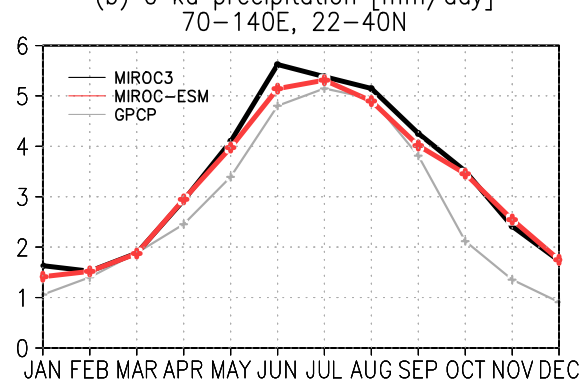

(d) precipitation change [\% of $0 \mathrm{ka}]$ $70-140 \mathrm{E}, 22-40 \mathrm{~N}$

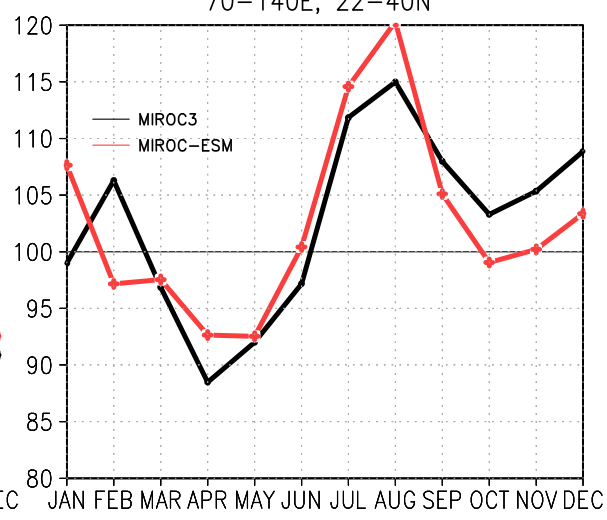

Fig. 1. 0 ka seasonal precipitation for MIROC-ESM (red lines) and MIROC3 (black lines) for the (a) African area $\left(20^{\circ} \mathrm{W}-30^{\circ} \mathrm{E}, 8-24^{\circ} \mathrm{N}\right)$ and (b) Asian area $\left(70-140^{\circ} \mathrm{E}, 22-40^{\circ} \mathrm{N}\right)$. The GPCP observational data (Adler et al., 2003) are also plotted with thin grey lines. The change in 6-0 ka (c, d) as a percentage of the 0 ka precipitation amount $(\%)$.

global level is offset by $+0.4^{\circ} \mathrm{C}$ to check whether global cooling affects precipitation enhancement over the Sahara.

M3Alai is another test for the vegetation feedback. Here, the climatological LAI obtained in the 0 and $6 \mathrm{ka}$ simulations using MIROC-ESM were used in MIROC3 AGCM experiments as boundary conditions instead of the observationbased LAI, which is prescribed in M3Amiroc3. The SSTs are the same as those for M3Amiroc3. All the sensitivity experiments were integrated for more than $25 \mathrm{yr}$, and climatologies of more than $18 \mathrm{yr}$ were used in the analyses. The averaging period for the sensitivity experiments is sufficiently long compared to previous studies with similar experimental settings (Hall and Valdes, 1997; Masson and Joussaume, 1997; Vettoretti et al., 1998). 
Table 3. Sensitivity experiments using the AGCM of MIROC3.

\begin{tabular}{lll}
\hline Exp. name & SST and sea ice & LAI \\
\hline M3Amiroc3 & MIROC3 & MIROC3 \\
M3Aesm & MIROC-ESM & MIROC3 \\
M3Aesmofs & MIROC-ESM6ka SST is offset & MIROC3 \\
M3Alai & MIROC3 & MIROC-ESM \\
\hline
\end{tabular}

\section{Representation of 0 ka climate}

\subsection{Atmospheric variables}

Regarding the model's basic performance, Watanabe et al. (2011) described, in full, the fidelity of the mean state and its variability reproduced in the model. They performed a 20th century transient experiment using MIROC-ESM, and obtained reasonable decadal global averaged temperature rises and falls when compared with observational data. Following on from Watanabe et al. (2011), we explain the representation of the temperature and precipitation at $0 \mathrm{ka}$, but the mean states of the 20th century experiment and the $0 \mathrm{ka}$ experiments show no major differences.

The temperature distribution is in good agreement with Jones et al. (1999), both for MIROC-ESM and MIROC3. Slight cooling in the $0 \mathrm{ka}$ simulations arises from differences in the greenhouse gas levels for the preindustrial era and those during the 20th century. The precipitation distributions suggest that the South Pacific Convergence Zone obtained with the two models is somewhat weaker than that described by the Global Precipitation Climatology Project (GPCP) observational dataset (Adler et al., 2003), but the Intertropical Convergence Zone (ITCZ) of the models is reasonably reproduced. The seasonality of the precipitation over the North African and Asian regions is generally well represented (Fig. 1a and b) compared to the GPCP data. The overestimation of precipitation over Northern Africa during boreal spring using MIROC3 is improved with MIROC-ESM.

\subsection{Oceanic variables}

Although SST biases relative to the World Ocean Atlas 1998 (World Ocean Atlas, 1998) are more significant over the Pacific Ocean for MIROC-ESM, with cooler tropics and warmer high latitudes, both models simulate the global SSTs reasonably well (Fig. 2). The reason for the positive SST bias in MIROC-ESM over the northern Pacific and Atlantic Ocean is thought to be the overestimation of low-level clouds (Watanabe et al., 2011). Note that generally negative biases are expected because of a difference between the time of the experimental $0 \mathrm{ka}(1850 \mathrm{AD})$ and that of the observations in the 20th century.

The sea-surface salinity was also compared with data from the World Ocean Atlas 1998 (data not shown). The models reproduce the global distribution fairly well, for example the

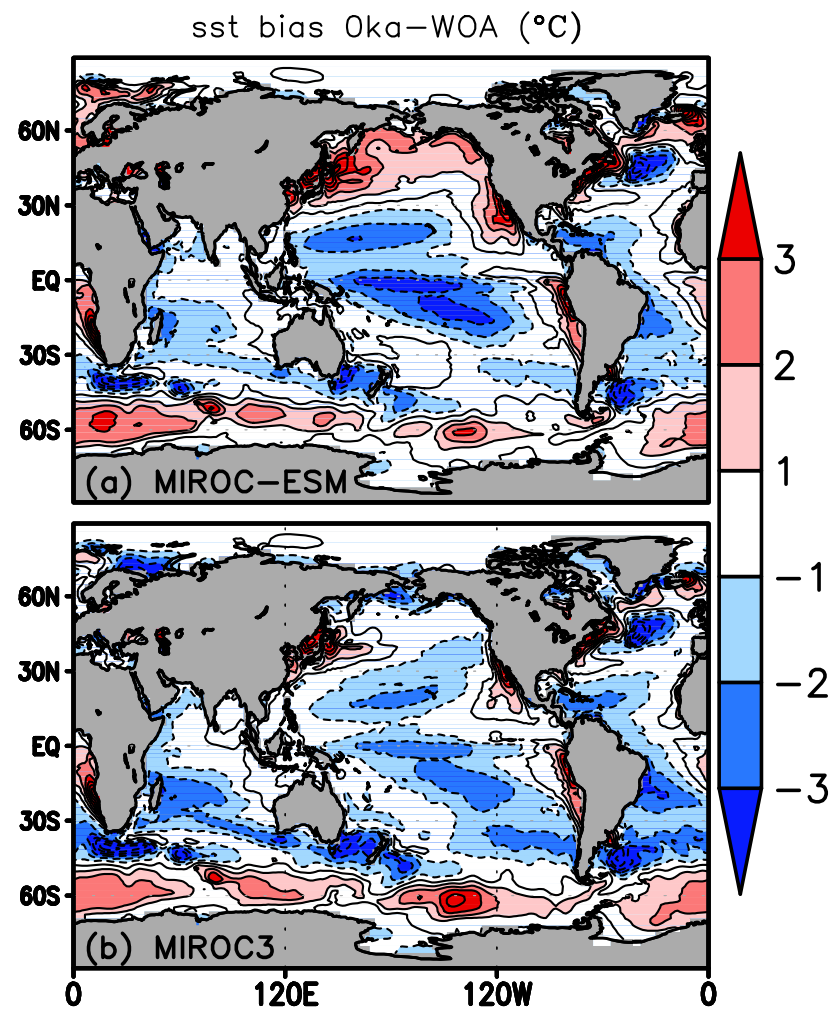

Fig. 2. $0 \mathrm{ka}$ annual SST biases in (a) MIROC-ESM and (b) MIROC3 compared with the World Ocean Atlas 1998.

saline area over mid-latitudes, salinity contrast between the Atlantic Ocean and Pacific Ocean, and freshwater over the Arctic Sea and the Warm Pool.

The peak values of the Atlantic Meridional Overturning Circulation are 17.0 Sv for MIROC-ESM and 19.2 Sv for MIROC3. These values are reasonable compared with observational based estimates, i.e. 17.2 Sv (Smethie and Fine, 2001) and, $18 \mathrm{~Sv}$ with 3 to $5 \mathrm{~Sv}$ error (Talley et al., 2003).

\section{Global changes at $6 \mathrm{ka}$}

\subsection{Atmospheric changes at $6 \mathrm{ka}$}

The 6-0 ka temperature changes are analyzed for JuneSeptember (JJAS) and December-February (DJF) (Fig. 3). We analyze JJAS, and not June-August, to capture the feature of the prolonged boreal summer under the $6 \mathrm{ka}$ forcing, as many previous studies on $6 \mathrm{ka}$ have done. Both MIROCESM and MIROC3 show warming over most of the boreal continents following the $6 \mathrm{ka}$ insolation change in JJAS. The lower warming over North America in MIROC-ESM compared to MIROC3 is more consistent with what the archive of proxy records suggests (Bartlein et al., 2011). The two models show slight cooling over the tropical ocean and the African and Asian monsoon regions, which is caused by 


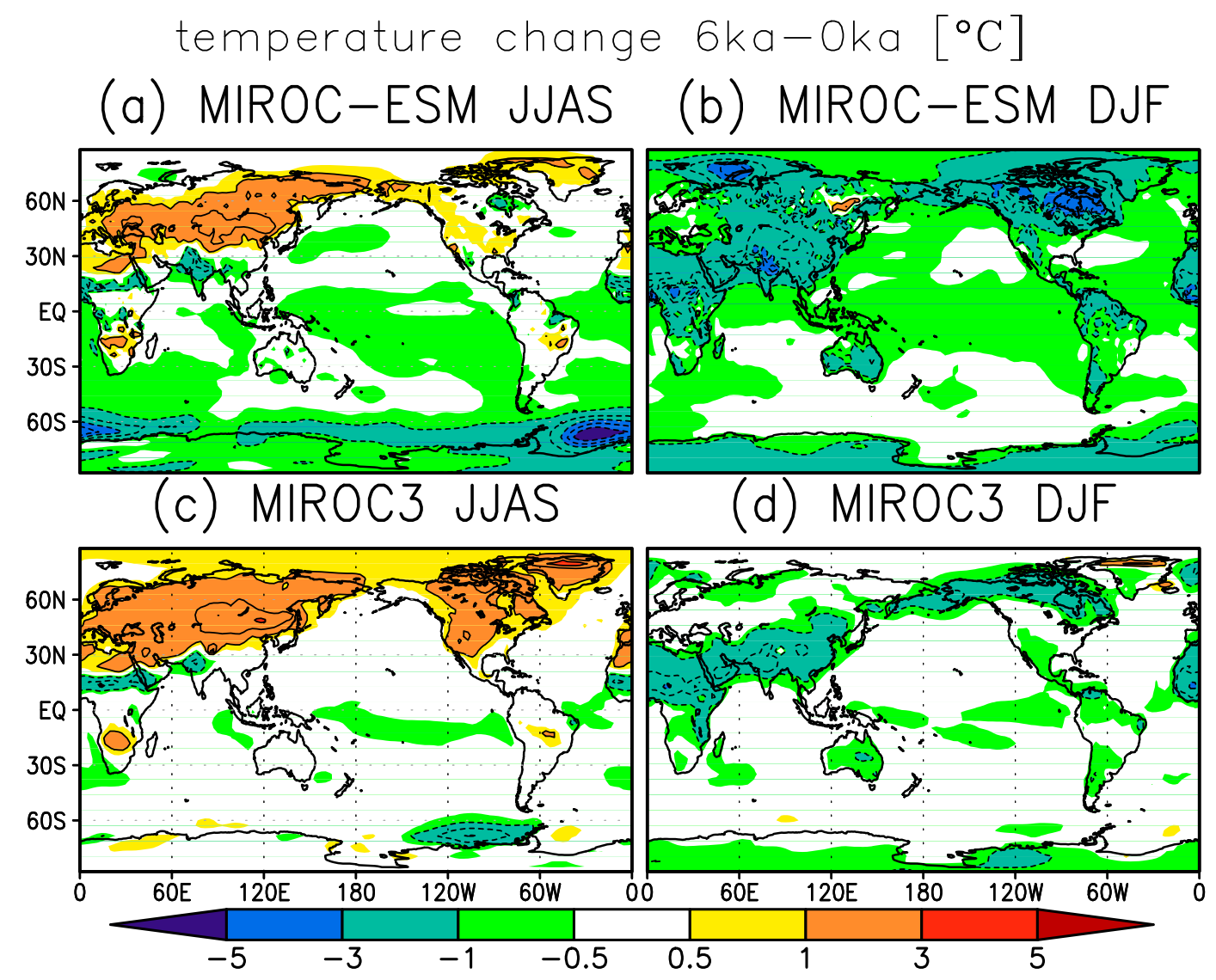

Fig. 3. 6-0 ka temperature changes at a height of $2 \mathrm{~m}\left({ }^{\circ} \mathrm{C}\right)$ in JJAS (left panels) and DJF (right panels) for MIROC-ESM (upper panels) and MIROC3 (lower panels).

strengthened monsoon activity. The Southern Ocean in JJAS is cooled more in MIROC-ESM. If the temperature were to respond simply to the radiation change at $6 \mathrm{ka}$, it would fall. In DJF, most of the continents become cooler following the insolation change at $6 \mathrm{ka}$. MIROC-ESM indicates greater cooling than MIROC3. Both models simulate cooling during the boreal winter and warming in the boreal summer over the Northern Hemisphere and slightly lower net temperature changes at $6 \mathrm{ka}$ compared to $0 \mathrm{ka}$ but MIROC-ESM simulates a larger temperature drop $\left(-0.65^{\circ} \mathrm{C}\right)$ than MIROC3 does $\left(-0.26^{\circ} \mathrm{C}\right)$. This must be due to differences in the AGCM components (e.g. clouds, aerosols and so on) and/or the vegetation scheme of the two models. However, the difference is too small to judge which model simulates changes closest to those suggested by the proxy records.

The global atmospheric circulation is also affected. MIROC-ESM and MIROC 3 show changes generally consistent with the Walker circulation (Fig. 4). The divergence from India to Southeast Asia in JJAS is greater and shifts westward at $6 \mathrm{ka}$. The changes are most pronounced over northern Africa. The area of pronounced northward shift of the latitudes of peak precipitation in JJAS at $6 \mathrm{ka}$ corresponds to the central area of the velocity potential changes. These circulation changes are consistent with the African and Asian monsoon enhancements. The convergence also strengthens and shifts westward over the Pacific Ocean. The 6 ka changes in DJF also suggest strengthening of the circulation but the greatest changes in divergence occur mainly over the Indian Ocean.

We see a general resemblance between the precipitation changes at $6 \mathrm{ka}$ obtained by MIROC-ESM and MIROC3 (Fig. 5). The spatial correlation coefficient of the two models is 0.69 for JJAS and 0.64 for DJF. In JJAS, an enhanced precipitation belt from the equator to the Sahel regions over the African continent is seen in both models. Additionally, there is a common region of enhanced precipitation over northern India accompanied by weakened precipitation over southern India, suggesting enhancement of the African and Asian monsoon systems. The details are discussed in Sect. 5. The latitudes of peak precipitation (indicating the position of ITCZ) shift northward over the Atlantic Ocean, and the African and Asian continents, consistent with the enhancement of the African and Asian monsoons, whereas over the Pacific Ocean, they do not change position and precipitation weakens (Figs. 4 and 5). In DJF, precipitation is enhanced over the Indian Ocean but reduced over the continents and 


\section{Walker Cell [1e6 m2/sec] 6ka-Oka \& peak latitude of prec. Oka, $6 \mathrm{ka}$}

(a) MIROC-ESM JJAS
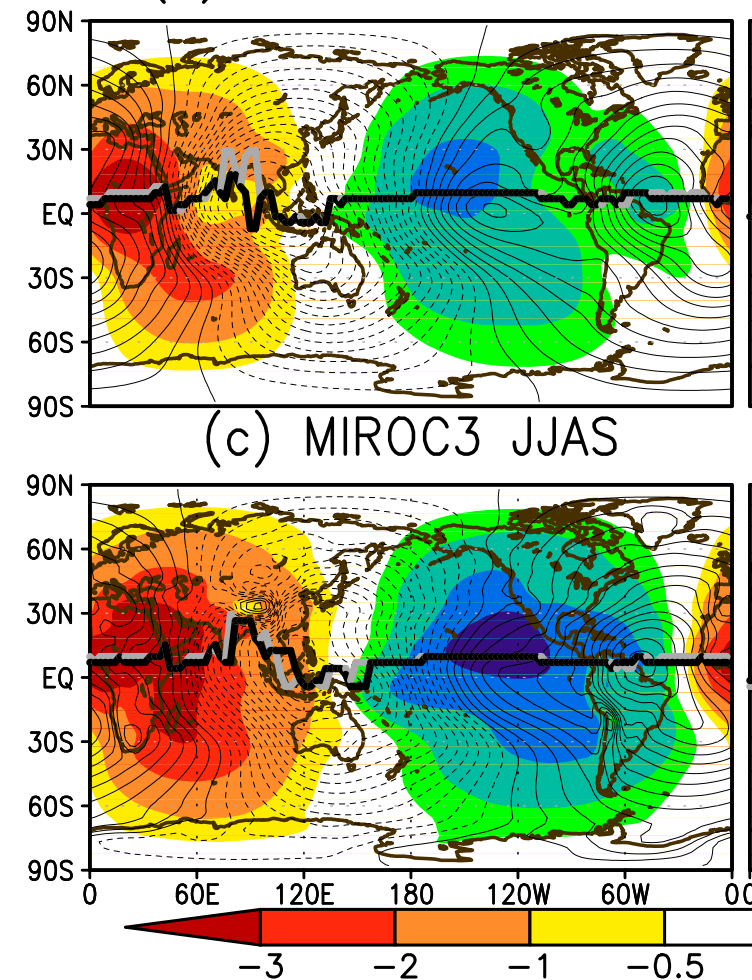

(b) MIROC-ESM DJF
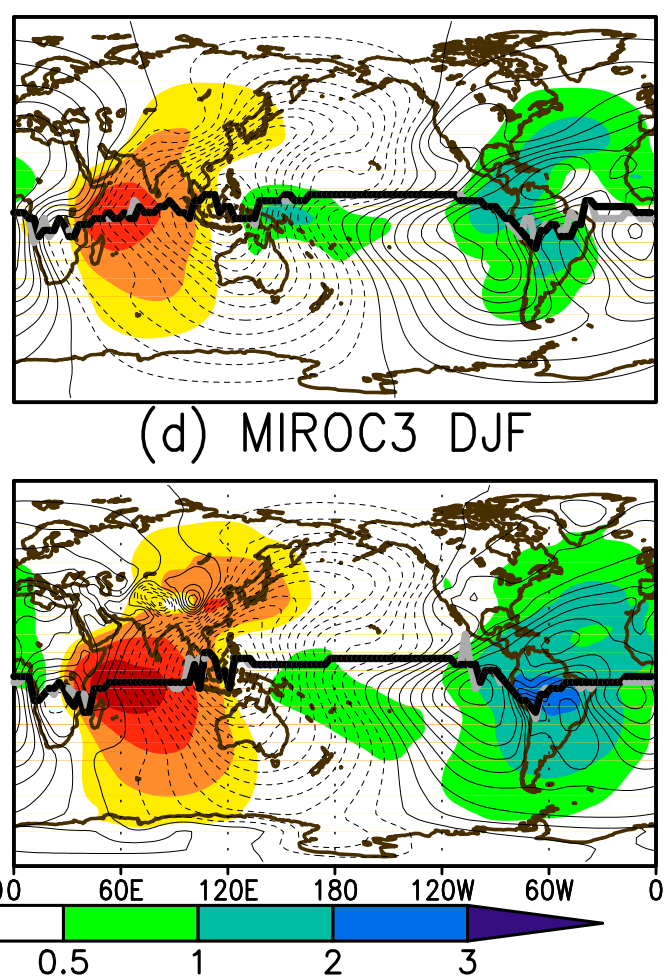

Fig. 4. Deviation from the zonal mean of the velocity potential at a pressure level of $200 \mathrm{hPa}\left[10^{6} \mathrm{~m}^{2} \mathrm{~s}^{-1}\right]$ and the latitudes of the peak of the precipitation. 6-0 ka changes (shading) in JJAS (left panels) and DJF (right panels) are plotted for MIROC-ESM (upper panels) and MIROC3 (lower panels). The thin contour lines are 0 ka values with intervals of $1 \times 10^{6} \mathrm{~m}^{2} \mathrm{~s}^{-1}$. The thick black and grey lines correspond to the latitudes of peak precipitation between $30^{\circ} \mathrm{S}$ and $30^{\circ} \mathrm{N}$ at 0 and $6 \mathrm{ka}$, respectively.

over the western tropical Pacific, suggesting weakened monsoon activity for both models. The ITCZ shifts southward over the Atlantic Ocean (Fig. 4).

Associated with the precipitation changes at $6 \mathrm{ka}$, soil moisture in the two models is enhanced over northern Africa, covering the Sahara, and northern India, but is reduced over most of Eurasia and North America (Fig. 6). The $6 \mathrm{ka}$ changes over Africa, India, and North America are consistent with proxy records of lake levels (Kohfeld and Harrison, 2000; Yu et al., 2000; Harrison et al., 2003). In particular, over Africa, not only moistening over the Sahara but also moistening over the tropical coastal area of Eastern Africa is reproduced by the models. The most westerly part of the the Indian Ocean where precipitation is enhanced in DJF corresponds to this area. Understanding the reduction in soil moisture over Eurasia and North America from the viewpoint of changes in the net water budget at $6 \mathrm{ka}$ is not straightforward. Modulation of the timing of and the amount of melted snow runoff, in particular, would influence the soil moisture during boreal spring for these areas. The colder spring at $6 \mathrm{ka}$ would delay the timing of snow melt, and in the following summer, stronger insolation would work to melt snow more rapidly during a shorter time compared to $0 \mathrm{ka}$, leading to more runoff into the river system and eventually to a reduction in soil moisture.

\subsection{Oceanic changes at $6 \mathrm{ka}$}

The spatial correlation coefficients for the SST changes at $6 \mathrm{ka}$ in the two models are 0.65 for JJAS and 0.56 for DJF (Fig. 7). Tropical SST cooling throughout most of the year and warming at northern high latitudes in JJAS are consistent for both models following the insolation changes. MIROCESM shows slightly cooler SST changes. MIROC-ESM simulates cooling whereas MIROC 3 simulates warming in the northern Atlantic Ocean. The JJAS cooling is unexpected from the radiation change at $6 \mathrm{ka}$ at the northern mid/high latitudes and also differs from the PMIP2 multi-model analyses (Braconnot et al., 2007). However, the seasonal variation 


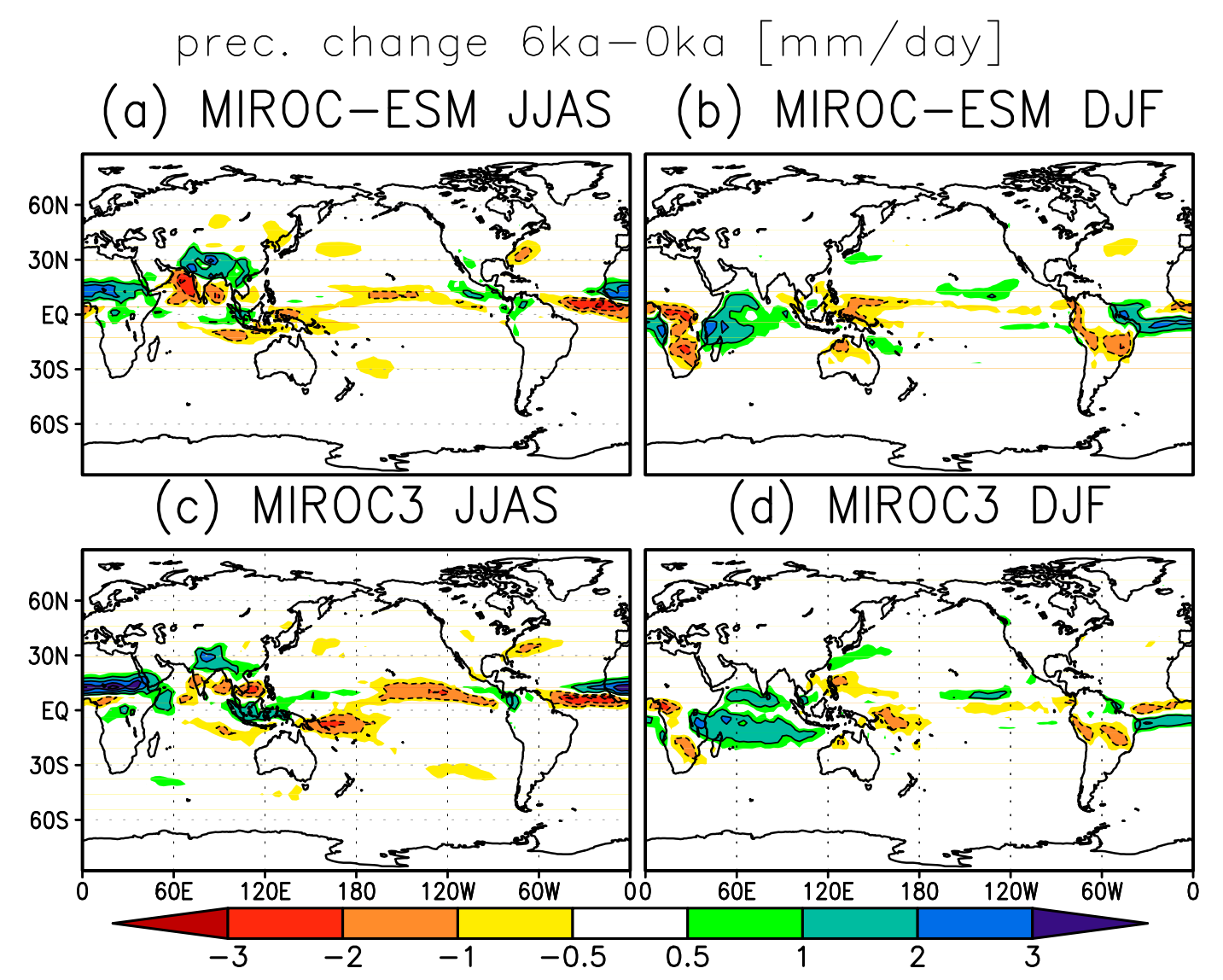

Fig. 5. The same as Fig. 3 but for precipitation changes $\left[\mathrm{mm} \mathrm{day}^{-1}\right]$.

in the SST changes at 6 ka over the northern Atlantic Ocean seems reasonable considering the radiation change but there is an offset of about $-0.5^{\circ} \mathrm{C}$ for MIROC-ESM compared with MIROC3 (Fig. 8). As a result, the JJAS change becomes negative. The lower SST at 6 ka compared with the change obtained from MIROC 3 is due to differences in the surface radiation budget (Fig. 8) which probably arises from the different radiation schemes. The longwave radiation changes at $6 \mathrm{ka}$ are about $3 \mathrm{~W} \mathrm{~m}^{-2}$ less than those obtained with MIROC3 throughout the year. Additionally, the change in shortwave radiation suggests weaker enhancement during the boreal summer associated with the enhancement of low-level cloud cover over this area. These differences in the 6 and $0 \mathrm{ka}$ surface radiation changes lead to lower SST during the winter and a barely positive SST change during the following summer. For the same reason, the SST change over the Pacific in MIROC-ESM is cooler compared to that in MIROC3.

In DJF the degree of cooling is higher for MIROC-ESM, especially over the northern high latitudes, and comes from the difference in the radiation schemes. The pattern of cooling is similar in both MIROC-ESM and MIROC3. The Southern Ocean warms according to MIROC3 whereas it cools according to MIROC-ESM.
Although there are differences in the ocean responses of the two models, the SST changes at $6 \mathrm{ka}$ are mostly within $\pm 1^{\circ} \mathrm{C}$. Proxy records are not able to determine which model simulation is better. However, there could be a possibility that the $0 \mathrm{ka}$ SST bias, which is larger in MIROC-ESM than in MIROC3 over the northern high latitudes (Fig. 2), may affect the results of the climate change simulations. The difference between the models is ultimately due to differences in the atmosphere and land modules because the OGCM components of the two models are identical.

The changes in the strength of the Kuroshio at $6 \mathrm{ka}$ are less than $1 \mathrm{~Sv}$ for both models (Fig. 9), which suggest that the difference in the level of SST cooling for the two models comes not from the difference in the modulation of the oceanic circulation but from the difference in the radiation at the sea surface. On the other hand, the changes in the Atlantic for the two models have different amplitudes, though the patterns are similar (the spatial correlation coefficient of the two models is 0.69 for the Atlantic, and 0.49 for the Pacific) (Fig. 9). MIROC3 simulates a strengthening of more than $5 \mathrm{~Sv}$ for the Gulf Stream at $6 \mathrm{ka}$, whereas MIROC-ESM simulates a change of only $1 \mathrm{~Sv}$. This change in heat transport also supports the difference between the changes in the North Atlantic temperatures of the two models. The difference 
dsoil moisture $[\mathrm{kg} / \mathrm{m} 2]$ ANN
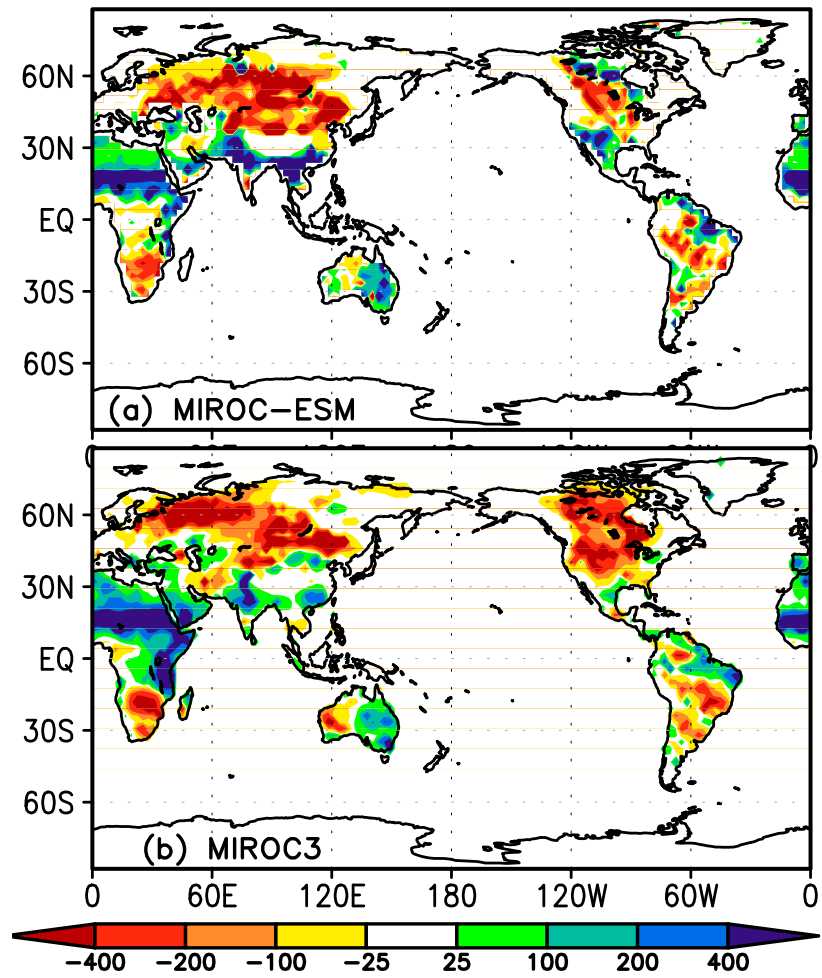

Fig. 6. 6-0 ka net soil moisture change $\left(\mathrm{kg} \mathrm{m}^{-2}\right)$ for (a) MIROCESM and (b) MIROC3.

between the subtropical gyre responses of the two models can be attributed to the surface wind stress differences because the oceanic parts of the two models are identical. The net increase in the surface wind stress is about $0.01 \mathrm{~N} \mathrm{~m}^{-2}$ along the direction of the Gulf Stream for MIROC3 over the area of the strengthened Gulf Stream, whereas MIROC-ESM simulates no large changes in the surface stress at $6 \mathrm{ka}$. The surface wind stress change at $6 \mathrm{ka}$ is partly due to the difference in the level of warming over the North American continent and resultant sea level pressure changes, which must be a result of the differences in the atmosphere, with the lowlevel cloud representation and land processes of the two models being the likely sources.

The sea ice extent and deep water formation sites in the Northern Hemisphere at $0 \mathrm{ka}$ are reproduced reasonably well by the two models (data not shown). However, in the Southern Hemisphere, the sea ice extent obtained with the two models are both smaller than the boundary condition of Atmospheric Model Intercomparison Project II (Hurrell et al., 2008), which results from the anomalously high SST bias indicated in Fig. 2.

The sea ice extent does not change drastically between 0 and $6 \mathrm{ka}$ according to the two models probably because of the weak radiation forcing. However, associated with the Southern Ocean cooling in MIROC-ESM, there is a greater extent of sea ice around Antarctica at $6 \mathrm{ka}$. In the Northern Hemisphere, associated with the northern warming in the boreal summer, the summer sea ice extent at $6 \mathrm{ka}$ is reduced in both models. Changes in winter at $6 \mathrm{ka}$ are small (data not shown). Because the sea ice doesn't extend further south at $6 \mathrm{ka}$, the SST cooling cannot be attributed to the change in sea ice extent.

Concerning the thermohaline circulation, neither model indicates a large change in the Atlantic Meridional Overturning Circulation at $6 \mathrm{ka}$. The peak values are $17.0 \mathrm{~Sv}$ at $0 \mathrm{ka}$ and 17.7 Sv at $6 \mathrm{ka}$ in MIROC-ESM, and 19.2 and $20.5 \mathrm{~Sv}$ at 0 and $6 \mathrm{ka}$ in MIROC3. Therefore, the change in the thermohaline circulation would have little effect on 6 ka climate change.

\subsection{Vegetation responses in MIROC-ESM}

In MIROC-ESM, the coupling between MATSIRO and SEIB-DGVM is relatively lax owing to the structural discrepancies between the two modules, and therefore some ecological changes predicted in the terrestrial ecosystem module are not reflected in MATSIRO. For example, changes in plant functional type composition and its spatial pattern modify the terrestrial biogeochemical processes but do not affect physical land processes except for those associated with the LAI. However, it is worth checking such internally predicted ecological information in SEIB-DGVM, because it demonstrates the potential of MIROC-ESM to reproduce vegetation feedback on the climate input from the AGCM part of MIROC-ESM. Over the Sahel region, grassland shifts about 1 grid northward and the tropical rainforest expands northward at $6 \mathrm{ka}$ (Fig. 10a and b). Although the most frequent vegetation types do not shift by more than one grid $\left(2.79^{\circ}\right)$, permanent desert reduces substantially (Fig. 10c and d). Such sporadic vegetation coverage over much of the Sahara may leave pollen proxy records.

The boundary of tundra grassland over Siberia shifts northward by about 1 grid which is associated with the warming in boreal summer. This is consistent with what has been reported by Bigelow et al. (2003) and O'ishi and Abe-Ouchi (2011). The forest types at mid-latitudes to high latitudes in Eurasia also generally shift northward.

The variable passed to MATSIRO, LAI, is enhanced significantly over tropical Africa, the Indian sub-continent and eastern Siberia. Over the rest of the land, there are patchy changes. Because the change in LAI is not linearly correlated with albedo, we have tested the effect of the LAI simulated in MIROC-ESM using a set of sensitivity experiments, M3Alai, which are described in Sect. 5.3.4. 


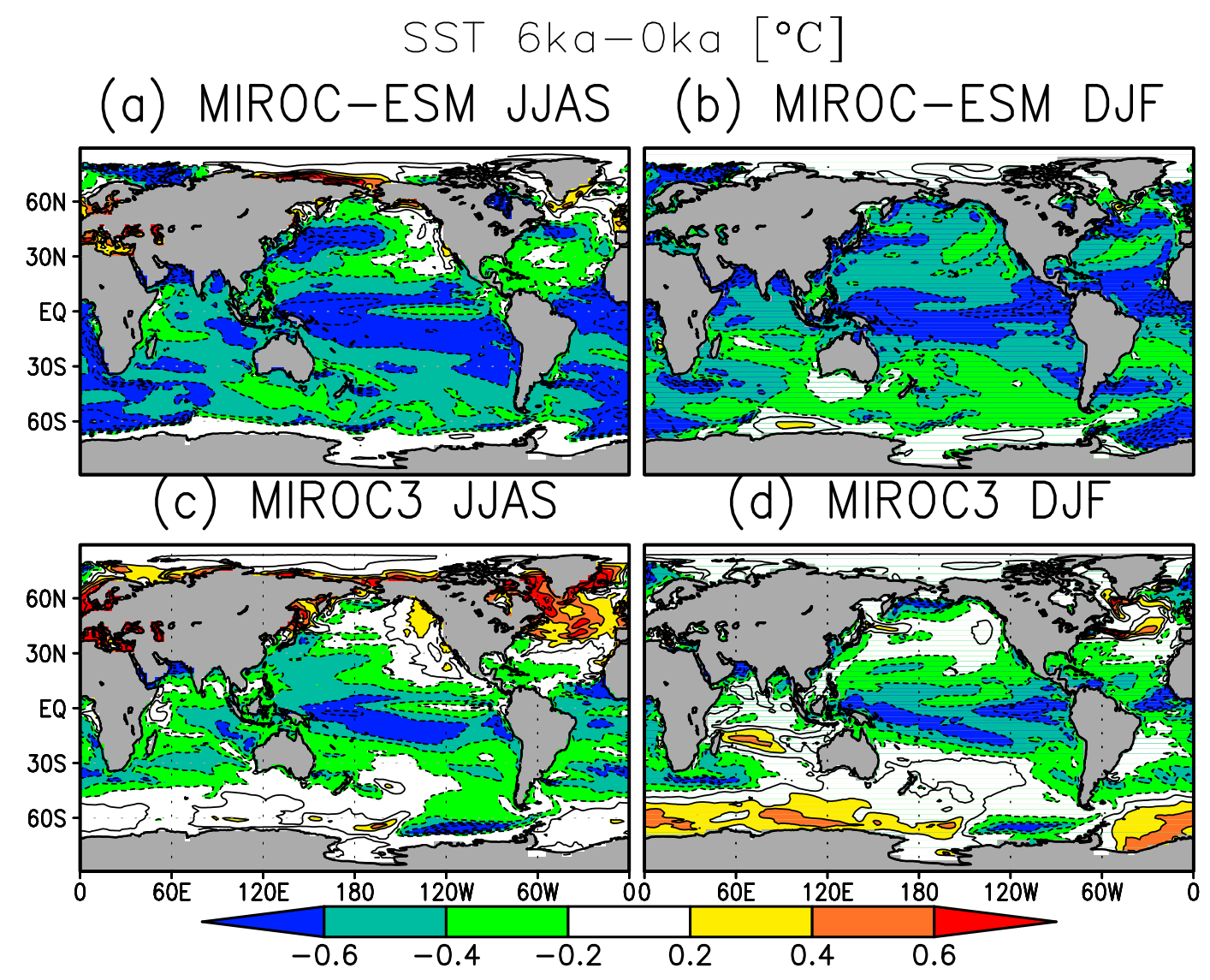

Fig. 7. The same as Fig. 3 but for the SST change $\left({ }^{\circ} \mathrm{C}\right)$.

\section{Summer monsoon changes at $6 \mathrm{ka}$}

\subsection{Overview of global summer monsoon changes at $6 \mathrm{ka}$}

Associated with the ITCZ changes at $6 \mathrm{ka}$ explained in Sect. 4.2, the Asian and northern African monsoon activities in the Northern Hemisphere summer are enhanced at $6 \mathrm{ka}$ in both MIROC models (Fig. 5). Sea-level pressure changes at $6 \mathrm{ka}$ (figures not shown) suggest lower air pressure over the continents in JJAS, which is consistent with the enhancement of the summer monsoon. The two models reveal generally consistent changes at $6 \mathrm{ka}$.

Both the MIROC-ESM and MIROC3 simulations for the 0 ka climate capture the various monsoon systems around the globe reasonably well (Fig. 11a and d). However, the monsoon precipitation index (MPI, the ratio of local summer rainfall to the annual total, Wang et al., 2012) over the Western Sahara obtained with MIROC3 is too high and the North American monsoon, which is improved in MIROC-ESM when compared with the observed MPI (Kim et al., 2011), is not well represented. In the $6 \mathrm{ka}$ simulations, the regional monsoons bear a close resemblance to the pluvial maxima (Fig. 11b and e). However, it is evident that the northern limit of the northern African monsoon extends further northward in association with the enhanced MPI (Fig. 11c and f). Indeed, the areal extent of the global monsoon domain generally varies in tandem with the change in the rainfall seasonality; the expansion (retreat) tends to coincide with the amplified (reduced) local summer rainfall. The region of large MPI over northern Africa, including the Sahara, and over the Arabian Peninsula, and the northern edge of the monsoon domain expand northward at $6 \mathrm{ka}$. MIROC-ESM shows that the enhancement of the MPI covers much of the Sahara whereas MIROC3 shows that the enhancement is limited to the eastern Sahara region. This could be related to the difference in the MPI representations for $0 \mathrm{ka}$, i.e. too much precipitation in MIROC3 (Fig. 1a and Nd). Although the global monsoon domain hardly changes at $6 \mathrm{ka}$, the austral summer monsoons are generally weaker. Additionally, both models reveal a decrease in precipitation over the Southern Hemisphere continents for DJF at $6 \mathrm{ka}$ (Fig. $5 \mathrm{~b}$ and d). This is consistent with the $6 \mathrm{ka}$ orbital forcing and also the results of a previous study (Liu et al., 2004).

No large 6 ka changes are observed in the North American monsoons according to the two models. Major changes are seen in the northern African and Asian monsoons. In the following subsections, we focus on the northern African and 


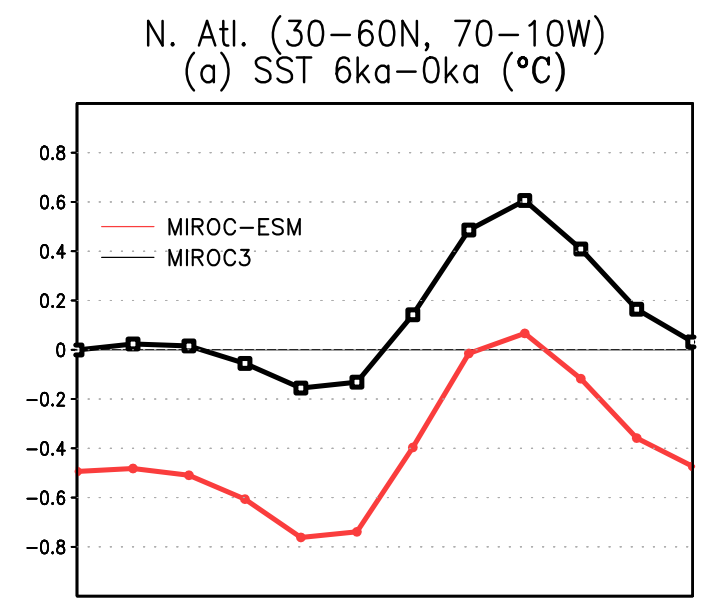

(b) down. rad. 6ka-0ka (W/m2)

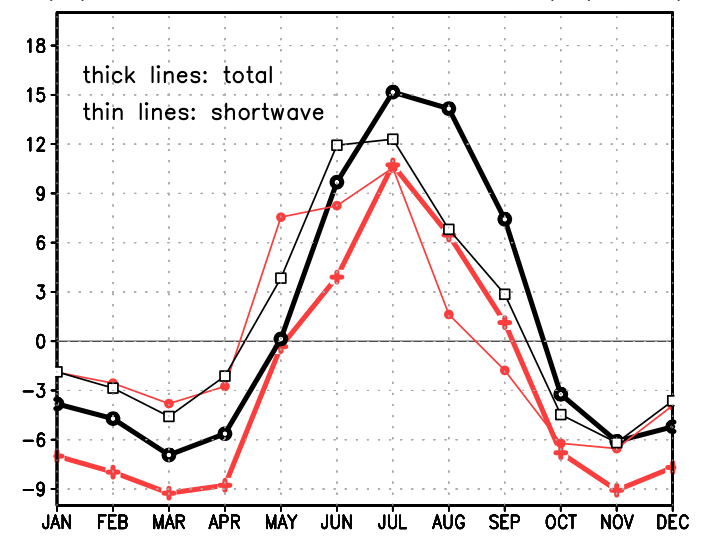

Fig. 8. (a) Seasonal evolution of the SST change $(6-0 \mathrm{ka})\left({ }^{\circ} \mathrm{C}\right)$ over the North Atlantic region $\left(30-60^{\circ} \mathrm{N}, 70-10^{\circ} \mathrm{W}\right)$ for MIROC-ESM (red line) and MIROC3 (black line). (b) The same as (a) but for the downward radiation change $\left(\mathrm{W} \mathrm{m}^{-2}\right)$ at the surface. The thick lines show total radiation changes and the thin lines shortwave radiation changes.

Asian monsoons, and we refer to the former as the African monsoon.

\subsection{Asian and African monsoons}

The two models simulate a northward shift of precipitation over Africa and Asia for JJAS (Fig. 12a and b). The circulation changes in the lower troposphere also indicate enhanced monsoon circulation at $6 \mathrm{ka}$. MIROC-ESM simulates slightly greater precipitation over the Sahara than MIROC3, which is also illustrated in Fig. 11c and f. The area of convective precipitation shifts northward in the Sahel and Sahara regions according to both models (not shown). The strengthened vertical motion changes at a height of $500 \mathrm{hPa}$ at $6 \mathrm{ka}$ (Fig. 12c and d) are also consistent with the enhancement and northward expansion of the convective activities for the two models. The difference between the models is small but most pronounced in early summer. The 6 ka precipitation changes for
MIROC-ESM and MIROC3 suggest similar seasonal evolution but the onset of the African monsoon obtained with MIROC-ESM occurs a little earlier than that obtained with MIROC3, and the peak enhancement in the Asian region is higher for MIROC-ESM than for MIROC3 (Fig. 1c and d). The earlier strengthening of divergence in the upper troposphere over the Sahara at $6 \mathrm{ka}$ in MIROC-ESM supports the earlier onset of monsoon. The difference in the timing of the monsoon onset may be related to the representation of the climate at $0 \mathrm{ka}$. To investigate the latitudinal behavior in more detail, we plot the Hovmöller diagrams of the $6 \mathrm{ka}$ precipitation changes for the African and Asian areas (Fig. 13). The two models simulate similar evolution of seasonal precipitation. For the African area, there is a northward shift of summer precipitation, with reduced precipitation during winter to spring. In MIROC-ESM, the precipitation covers the Sahara during early summer at $6 \mathrm{ka}$. The level of enhancement is insufficient to maintain vegetation over the Sahara; however, the enhancement is significant. The largest precipitation enhancements are seen between 10 and $15^{\circ} \mathrm{N}$ in August for the two models. The precipitation enhancement is higher in MIROC3 than in MIROC-ESM (Figs. 12a and b and 13a and c), as a result of increased warming over the Sahara in MIROC3 and an associated decrease in the sea level pressure.

The precipitation enhancement is discussed further in the following subsections. For the Asian area, both models simulate a northward shift of precipitation in summer, accompanied by a reduction in precipitation to the south. Both models indicate an enhancement and northward shift of the westerly for JJAS around $10^{\circ} \mathrm{N}$ over Africa and $20^{\circ} \mathrm{N}$ over South Asia. One difference between the two models is seen in the easterly over the Sahara region during the summer. It weakens in the case of MIROC-ESM, whereas MIROC3 does not show any large changes in the wind. In the former model, this difference in early summer leads to more moisture convergence over the Sahara and further enhancement of precipitation over that area.

Although the enhancement of the Asian monsoon precipitation in $6 \mathrm{ka}$ is well simulated in the two models, we find that it is still difficult to see the appreciable changes in the monsoon-desert coupling that is suggested to be driven by the Rossby wave response to the diabatic heating over India (Rodwell and Hoskins, 1996).

\subsection{Precipitation enhancement over the Sahara}

\subsubsection{Precipitation changes at $6 \mathrm{ka}$}

The differences between the precipitation over the Sahara in MIROC-ESM and that in MIROC3 are further investigated. The difference between the $6 \mathrm{ka}$ precipitation changes in the two models is most pronounced in early summer over the Sahara (Fig. 14). MIROC-ESM simulates enhancement of precipitation covering the Sahara whereas MIROC3 simulates no enhancement from May to June (MJ), while from July to 


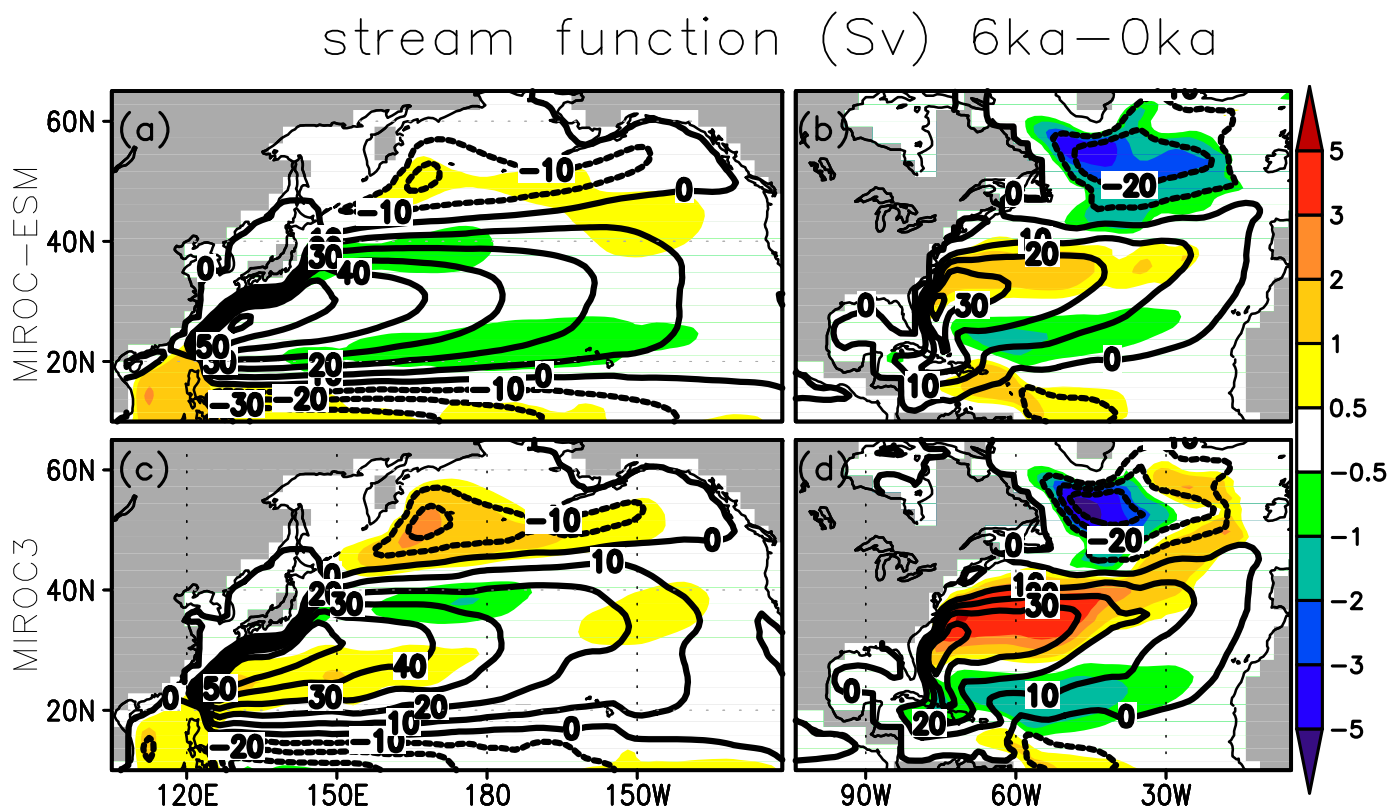

Fig. 9. Ocean surface stream functions (contours for $0 \mathrm{ka}$ ) and the changes at $6 \mathrm{ka}$ (colored shading) (Sv) for the Pacific and Atlantic sectors in the Northern Hemisphere, obtained using (a, b) MIROC-ESM and (c, d) MIROC3.

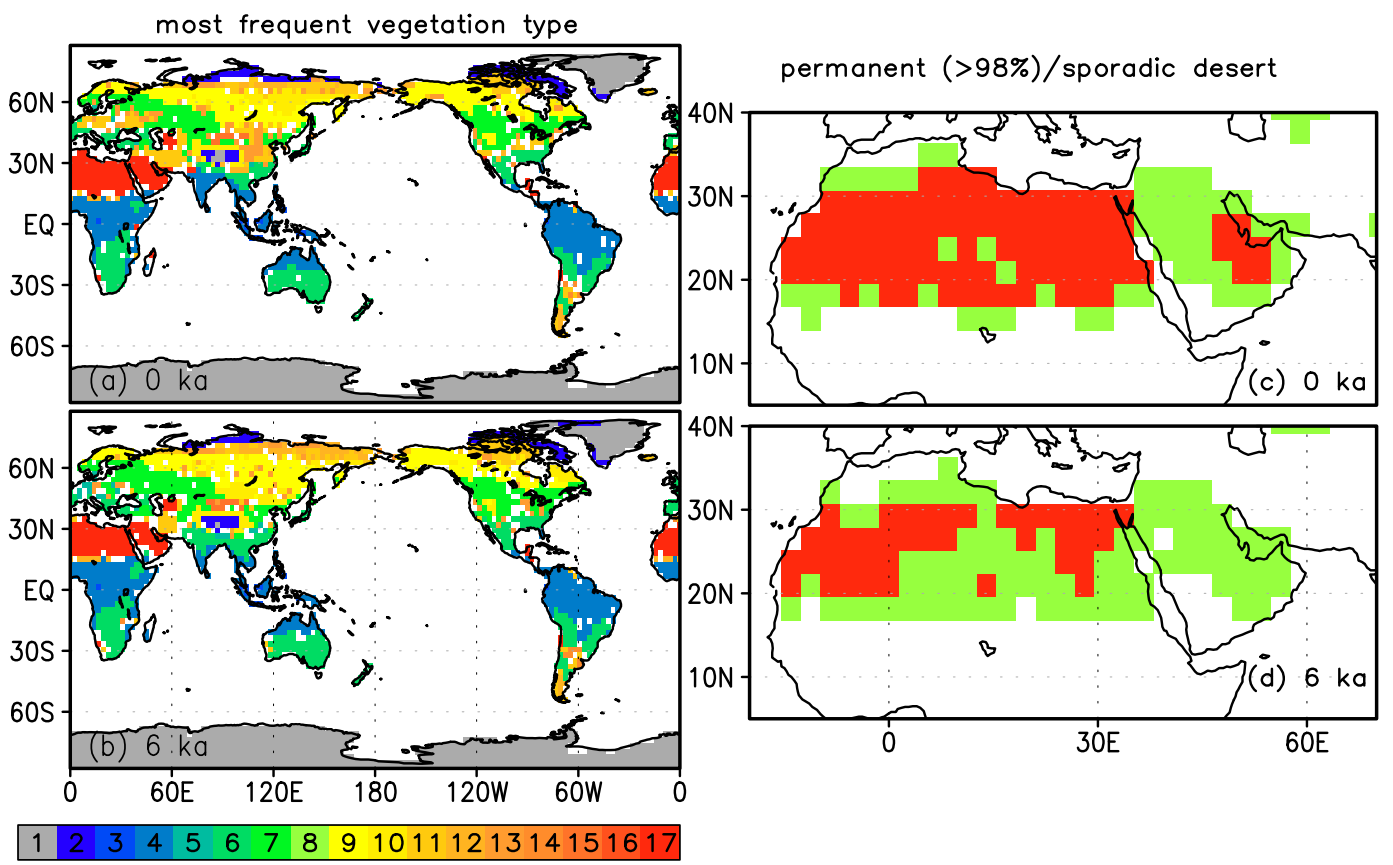

Fig. 10. Left panels: most frequent vegetation types in SEIB-DGVM with MIROC-ESM for 0 and 6 ka. The grids with no stable vegetation type $(>50 \%)$ are white. Numbers in the boxes at the bottom correspond to the vegetation types listed in Table 1. Right panels: desert areas shown in the left panels shaded in color for (c) $0 \mathrm{ka}$ and (d) $6 \mathrm{ka}$. The red grids indicate permanent desert (>98\%), whereas green grids indicate sporadic desert. 
(a) MIROC-ESM Oka

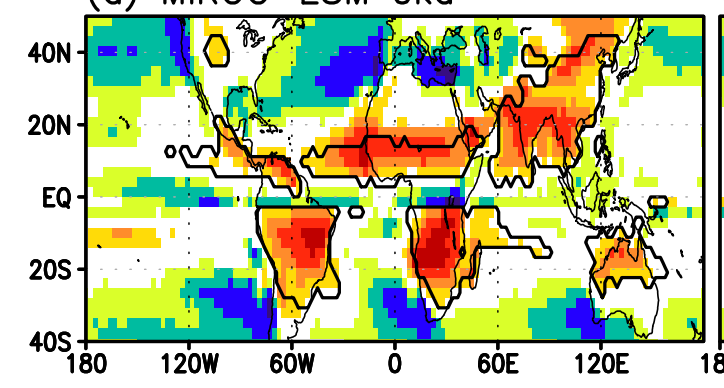

(b) MIROC-ESM $6 \mathrm{ka}$

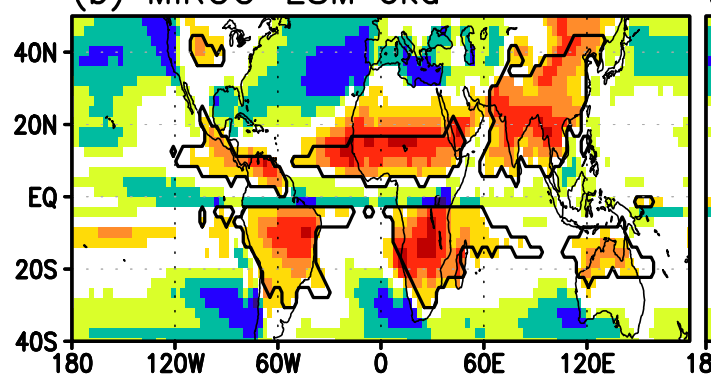

(c) MIROC-ESM 6ka-Oka

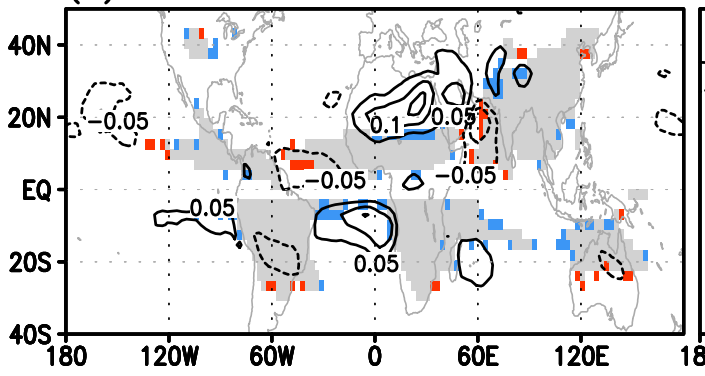

(d) MIROC3 Oka

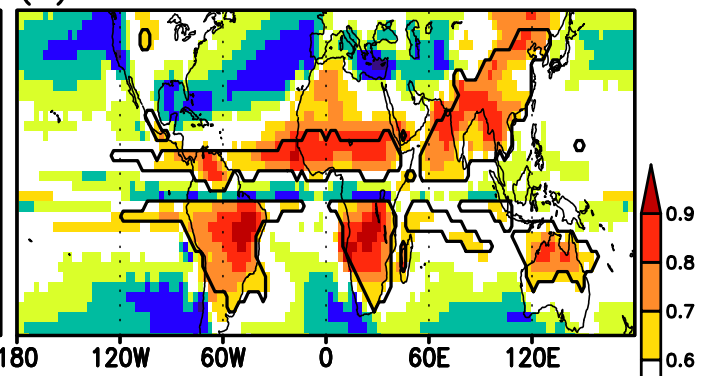

(e) MIROC3 $6 \mathrm{ka}$

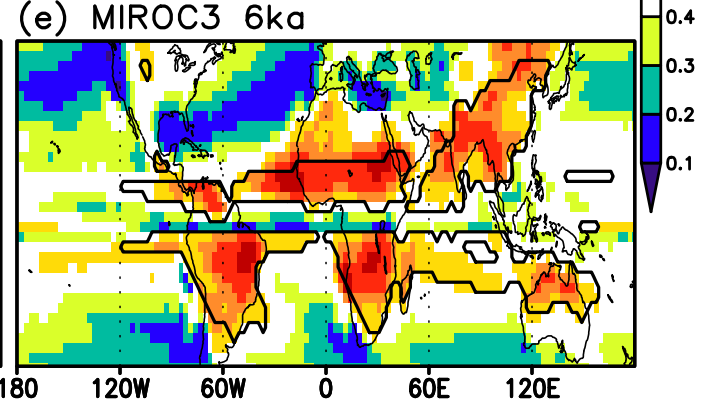

(f) MIROC3 $6 \mathrm{ka}-0 \mathrm{ka}$

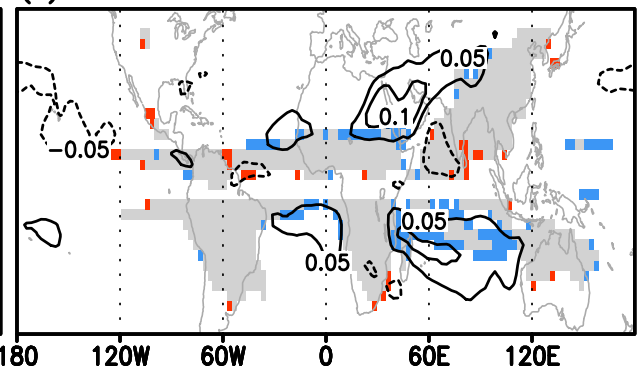

Fig. 11. Global monsoon precipitation domain (contour) and MPI (shading) for the $0 \mathrm{ka}$ (top panels) and $6 \mathrm{ka}$ (middle panels) climates obtained using MIROC-ESM (left panels) and MIROC3 (right panels). In (c, f) for the change in the monsoon domain, the grey areas indicate the regions identified in common, and the blue (red) area indicates the area of expansion (retreat) in the $6 \mathrm{ka}$ simulations. The contours denote the 6-0 ka MPI changes.

September (JAS), the two models simulate a similar northward shift in the precipitation.

\subsubsection{SST feedback}

It is known that SST variability greatly affects the African monsoon (Rodriguez-Fonseca et al., 2011; Mohino et al., 2011; Losada et al., 2010a,b; Fontaine et al., 2010; Bader and Latif, 2003; Vizy and Cook, 2001). Therefore, the SST at $6 \mathrm{ka}$ is a potential source of precipitation change. This is investigated by some sensitivity experiments using the MIROC3 AGCM. We performed two sets of 0 and $6 \mathrm{ka}$ experiments; one used climatological SSTs simulated by MIROC-ESM (M3Aesm) as the oceanic boundary condition, and the other used climatological SSTs simulated by MIROC3 (M3Amiroc3) as listed in Table 3. This test does not directly identify the reason for the $6 \mathrm{ka}$ precipitation change simulated in MIROC-ESM but can imply the effect of the SST change on precipitation changes.

Note that the atmosphere-to-ocean interaction is ignored in these sensitivity experiments. To this end, however, we firstly compare the fully coupled MIROC3 and M3Amiroc3 to check if the differences in the experimental settings (i.e. oneway coupling vs full coupling of ocean) can affect the monsoon changes at $6 \mathrm{ka}$. The seasonal evolution of the precipitation changes suggests that the $6 \mathrm{ka}$ precipitation changes in MIROC3 can be reproduced using M3Amiroc3 for the African area. However, there is a significant difference between MIROC3 and M3Amiroc3 for the Asian area (data not shown), implying that short-term SST variability and/or ocean-atmosphere interaction play a role in the Asian area. Therefore, we look at only the African area in the sensitivity experiments.

The Hovmöller diagrams in Fig. 15 show weak precipitation enhancement over the Sahara during MJ in M3Aesm, 
prec $[\mathrm{mm} / \mathrm{day}]+850 \mathrm{hPa}$ circ.

(a) MIROC-ESM

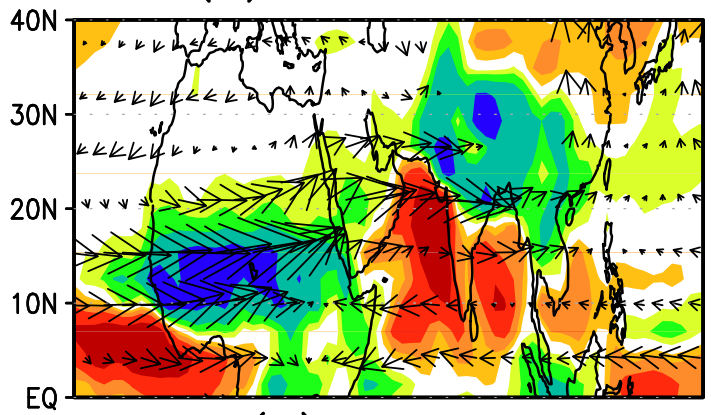

(b) MIROC3

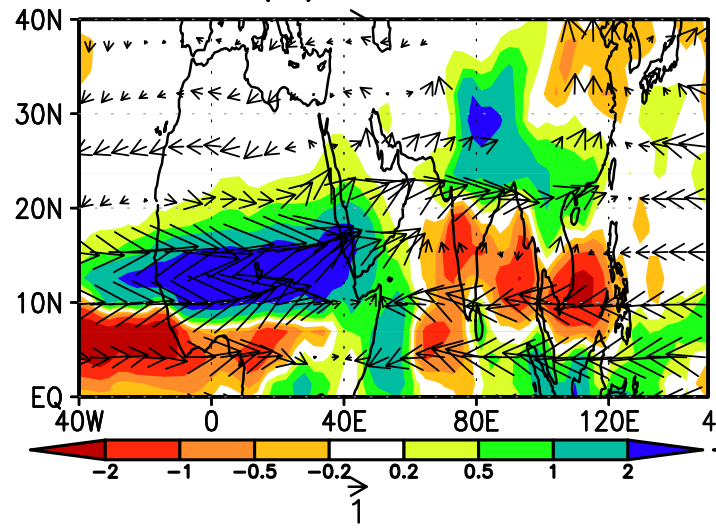

$500 \mathrm{hPa}$ omg $[\mathrm{hPa} / \mathrm{s}]$

(c) MIROC-ESM

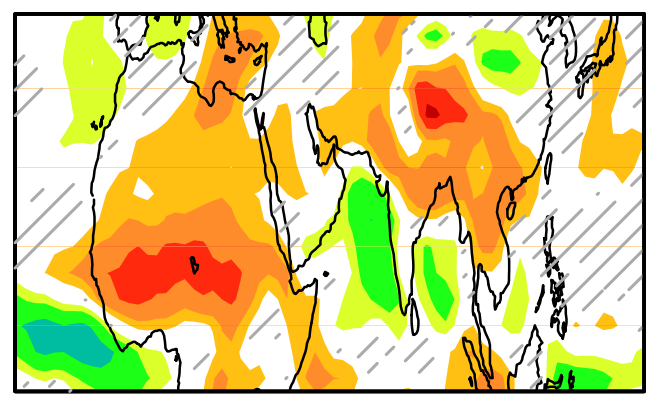

(d) MIROC3

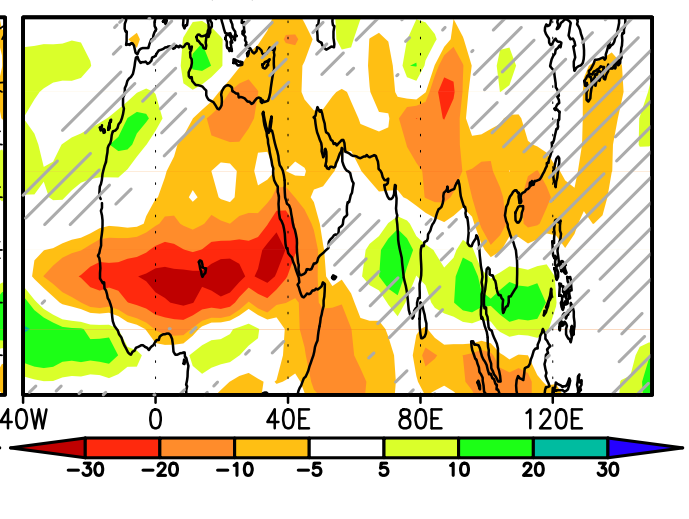

Fig. 12. Left panels: 6-0 ka precipitation changes (colored shading) and wind changes at $850 \mathrm{hPa}$ (arrows) in JJAS obtained with (a) MIROCESM and (b) MIROC3. Right panels: 6-0 ka change in vertical motion at $500 \mathrm{hPa}$ (colored shading) (hPa s ${ }^{-1}$ ) in JJAS obtained with (c) MIROC-ESM and (d) MIROC3. Areas where the change is insignificant based on a $t$ test (95\%) are shown hatched.

similar to that in MIROC-ESM (Fig. 13a), whereas this enhancement is not seen in M3Amiroc3. The precipitation changes in MJ for the Saharan area obtained from the sensitivity experiments (Fig. 16) suggest that the difference in precipitation enhancement over the Sahara is attributable to the different climatological SSTs. The largest precipitation enhancement at $6 \mathrm{ka}$ around 10 to $15^{\circ} \mathrm{N}$ in boreal summer is more pronounced in M3Amiroc3 than in M3Aesm, but seems to be comparable to the difference between MIROC3 and MIROC-ESM. Slightly more warming over the Sahara at $6 \mathrm{ka}$ in M3Amiroc3 than in M3Aesm is consistent with results from the coupled model experiments. Associated with these changes, the decrease in the sea level pressure over the Sahara at $6 \mathrm{ka}$ is more pronounced in M3Amiroc3 than in M3Aesm and this leads to a strong monsoon circulation shifting to the Sahel region, but not to the Sahara, further north.

M3Aesm simulates enhanced precipitation over the Sahara at $6 \mathrm{ka}$ whereas M3Amiroc 3 simulates reduced precipitation. Significant differences between MIROC-ESM and MIROC3 and between M3Aesm and M3Amiroc3 are indicated by the non-hatched areas in Fig. 16a and c. The 6 ka-to-0 ka precipitation ratios over the Sahara region $\left(20^{\circ} \mathrm{W}-30^{\circ} \mathrm{E}, 15-35^{\circ} \mathrm{N}\right)$ are $+42 \%$ for MIROC-ESM, $+2 \%$ for MIROC $3,+23 \%$ for M3Aesm, and $-8 \%$ for M3Amiroc3. This implies that differences in the SSTs of MIROC3 and MIROC-ESM can lead to precipitation differences over the Sahara. Although the weakening of the westerly in the lower troposphere at $6 \mathrm{ka}$ seen in MIROC-ESM is not seen in M3Aesm, during early summer, the divergence in the upper troposphere at $6 \mathrm{ka}$ is stronger in M3Aesm than in M3Amiroc3, consistent with what we observed in the coupled model experiments.

Although the precipitation amounts over the Sahel region for the sensitivity experiments resemble those from MIROC3, the MPI over the Sahara region at $0 \mathrm{ka}$ is higher for M3Amiroc3 than for M3Aesm, and M3Aesm gives a greater change in the MPI at $6 \mathrm{ka}$ than M3Amiroc3. This resembles the MPI over the Sahara region according to MIROC-ESM and MIROC3 (Fig. 11). The slight difference between the $0 \mathrm{ka}$ SST patterns in MIROC-ESM and MIROC 3 affects the precipitation amount at $0 \mathrm{ka}$, and it could also affect the precipitation enhancement at $6 \mathrm{ka}$.

On the other hand, the global SST cooling in the $6 \mathrm{ka}$ simulation using MIROC-ESM may be responsible for some changes in precipitation. To check how SST cooling affects 


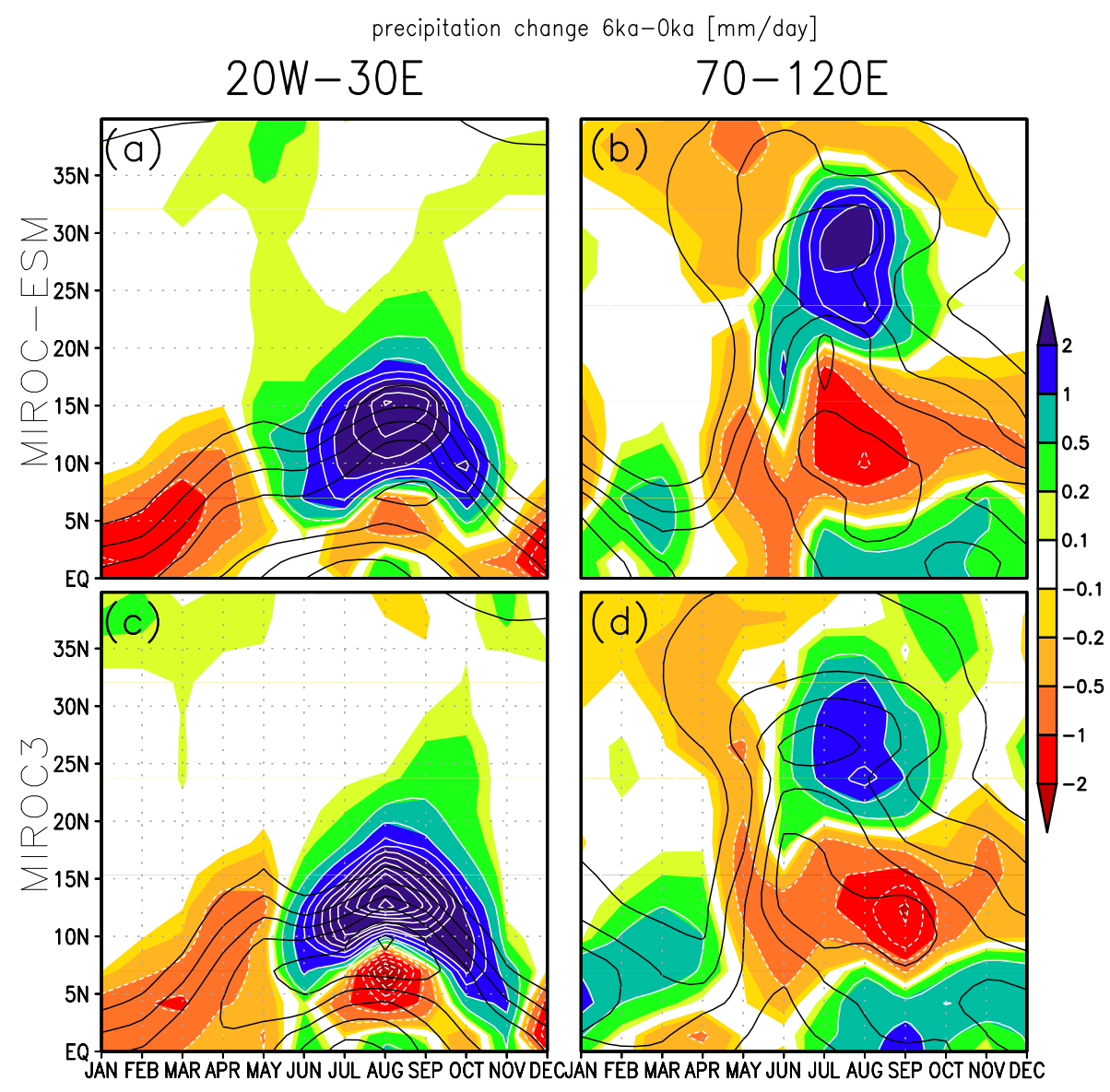

Fig. 13. Hovmöller diagrams for the northern African area (left panels) and Indian area (right panels) obtained with MIROC-ESM (upper panels) and MIROC3 (lower panels). Colors indicate the 6-0 ka precipitation change $\left(\mathrm{mm} \mathrm{day}^{-1}\right)$. Black lines denote the 0 ka precipitation amount in intervals of $2 \mathrm{~mm}_{\text {day }}{ }^{-1}$.

precipitation change over the Sahara, we compare results obtained with M3Aesm and M3Aesmofs. The enhancement is substantially reduced over the Sahara in MJ when using M3Aesmofs as shown in Fig. 15d. Therefore, the slightly cooled SSTs at $6 \mathrm{ka}$ in MIROC-ESM may also play a role in the precipitation enhancement in the early summer over the Sahara.

In summary, a little difference in the realization of SSTs can influence the precipitation enhancement over the Sahara region at $6 \mathrm{ka}$. The slightly cooler SST at $6 \mathrm{ka}$ in MIROCESM may also play a role.

\subsubsection{Ocean variability and the influence on the precipitation over the Sahara}

However the sensitivity experiments in the previous subsection consider the effect of the difference in climatological SSTs between the models, it is still possible that the modulation of the correlation between the year to year variability of the SSTs and the precipitation influences the net precipitation enhancement. In this subsection, we look into the correlation between the ocean variability and the African monsoon. The largest climatic variability in the atmosphere-ocean system is ENSO. The amplitudes of the ENSO variation for the $0 \mathrm{ka}$ simulations using MIROC-ESM and MIROC 3 are smaller than what was observed (standard deviation of 0.39 and 0.48 , respectively, as opposed to 0.92 for ECMWF $40 \mathrm{yr}$ Re-analyses; Roxy et al., 2011). Therefore, although we will not be able to make a quantitative statement, we can discuss this in a qualitative manner. At $6 \mathrm{ka}$, the amplitudes of the Niño3 indices were reduced both for MIROC3 (0.37 at $6 \mathrm{ka}$ ) and for MIROC-ESM (0.38 at 6 a). Weakening is consistent with previous modeling studies (Liu et al., 2000; Brown et al., 2008) and with what the proxy records suggest (Rodbell et al., 1999; Tudhope et al., 2001; McGregor and Gagan, 2004; Gagan et al., 2004). The Walker circulation strengthening (Fig. 4) and the intensified upwelling over the equatorial Pacific suggest consistency with the mechanism by which ENSO dampens at $6 \mathrm{ka}$, as proposed by Liu et al. (2000).

The correlation between ENSO and precipitation in JJAS (Fig. 17) reveals that there seems to be no large changes in the correlation patterns at 0 and $6 \mathrm{ka}$. The correlation 


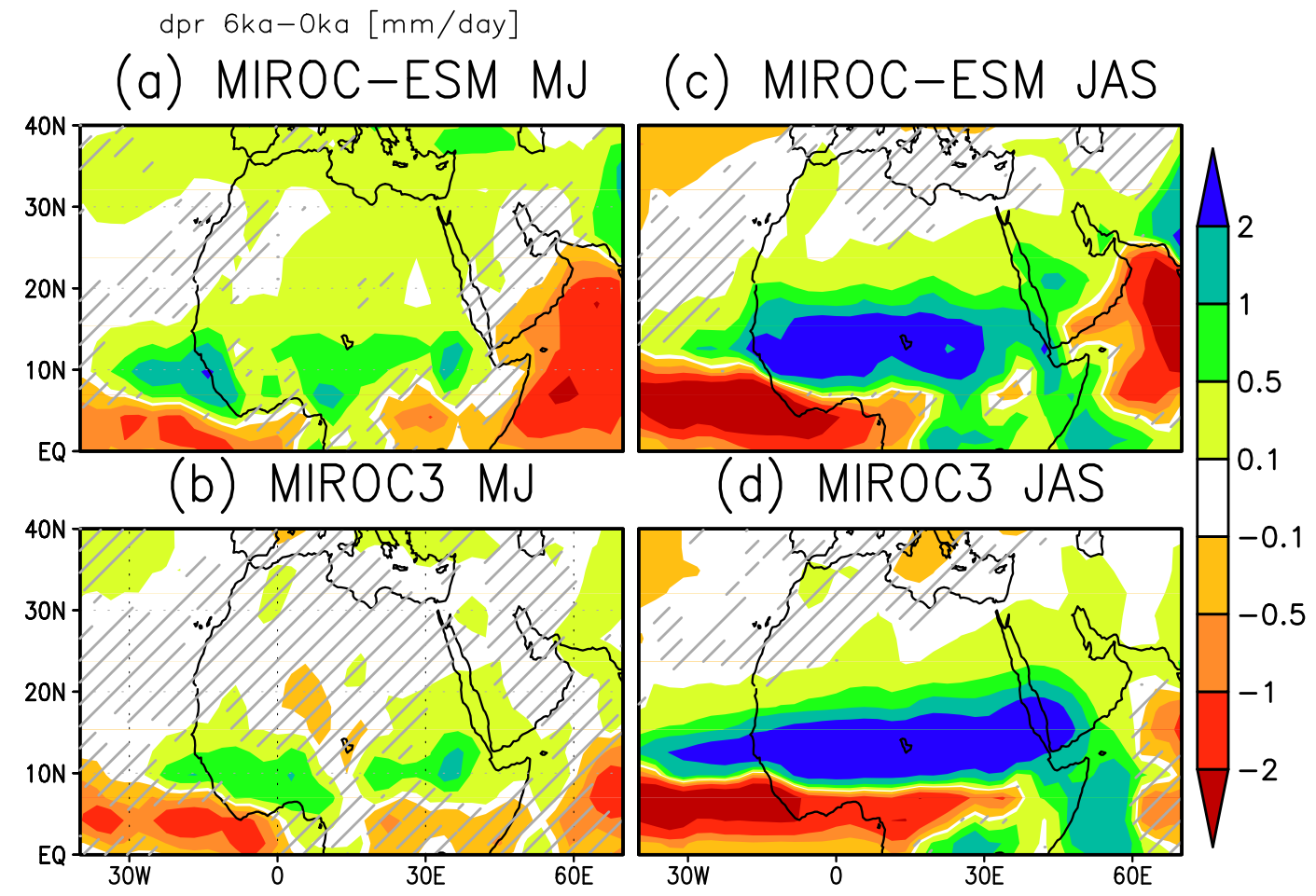

Fig. 14. 6-0 ka precipitation change (colored shading) $\left(\mathrm{mm} \mathrm{day}^{-1}\right)$ in MJ (left panels) and JAS (right panels) obtained with MIROC-ESM (upper panels) and MIROC3 (lower panels). The hatched areas denote regions where the precipitation amounts in 0 and $6 \mathrm{ka}$ do not differ significantly in a $t$ test $(95 \%)$.

coefficients over the Sahara area are small in both models. Also, the correlation between North African precipitation and ENSO does not change significantly in $6 \mathrm{ka}$ for both of the models. Therefore, it is unlikely that the modulation of the correlation with ENSO at $6 \mathrm{ka}$ affects the monsoon change significantly. However, compared to the observational data (Fig. 17e), it is obvious that the negative correlation over the African monsoon area is not well represented in the $0 \mathrm{ka}$ simulations of the two models. Improvements to the 0 ka representation (possibly through the ENSO amplitude) may affect the simulated change under 6 ka forcing.

Next, we look into the correlation between the year-toyear precipitation variability over the northern African subregional area and the global SST variability at 0 and $6 \mathrm{ka}$ (Fig. 18, plotted for MIROC-ESM only). The correlations between the precipitation over latitudes $0-10^{\circ} \mathrm{N}$ and the SSTs at 0 and $6 \mathrm{ka}$ are illustrated in Fig. $18 \mathrm{c}$ and f, respectively. Figure 18c suggests a strong positive correlation with the SST variability over the Gulf of Guinea at $0 \mathrm{ka}$. This is weaker at $6 \mathrm{ka}$ (Fig. 18f) (statistically significant according to a $t$ test), which possibly arises from the northward shift of the precipitation belt and the associated weakened precipitation over latitudes close to the Gulf of Guinea. The precipitation over dry regions $\left(10-15^{\circ} \mathrm{N}\right.$ and $\left.15-30^{\circ} \mathrm{N}\right)$ does not have such a strong correlation with the SST of nearby oceans at either 0 or $6 \mathrm{ka}$, as seen at tropical latitudes. Although the correlations are weak, the correlation coefficients for precipitation over semi-arid latitudes $\left(10-15^{\circ} \mathrm{N}\right.$, Fig. $18 \mathrm{~b}$ and e) suggest a strengthened positive correlation with the Mediterranean Sea and the area of the Atlantic Ocean at roughly the same latitudes at $6 \mathrm{ka}$ (statistically significant according to a $t$ test). The same tendency is seen in the precipitation over the desert (Fig. 18a and d) (statistically significant according to a $t$ test). Although precipitation-SST correlations are generally weak, the enhanced precipitation at $6 \mathrm{ka}$ correlates more positively to the SST at nearby latitudes of the Atlantic Ocean. The area of significant circulation change at $6 \mathrm{ka}$ (Fig. 12) coincides with this more positively correlated area. Lagged correlations are also analyzed but they are weaker than the correlations in Fig. 18, even though the spatial patterns are similar to one another. Although we only show MIROC-ESM to keep Fig. 18 simple, the results using MIROC3 are consistent with those of MIROC-ESM.

In summary, both ENSO-precipitation and precipitationSST correlations over the Sahara are weak for both models and for both 0 and $6 \mathrm{ka}$. This suggests that there is no significant change in the correlation between ocean-precipitation over the Sahara in either 0 or $6 \mathrm{ka}$. This could be partly due to the insufficient representation of $0 \mathrm{ka}$ climate variability by the MIROC-models but it also supports the validity of the sensitivity experiments at least for the MIROC models. 


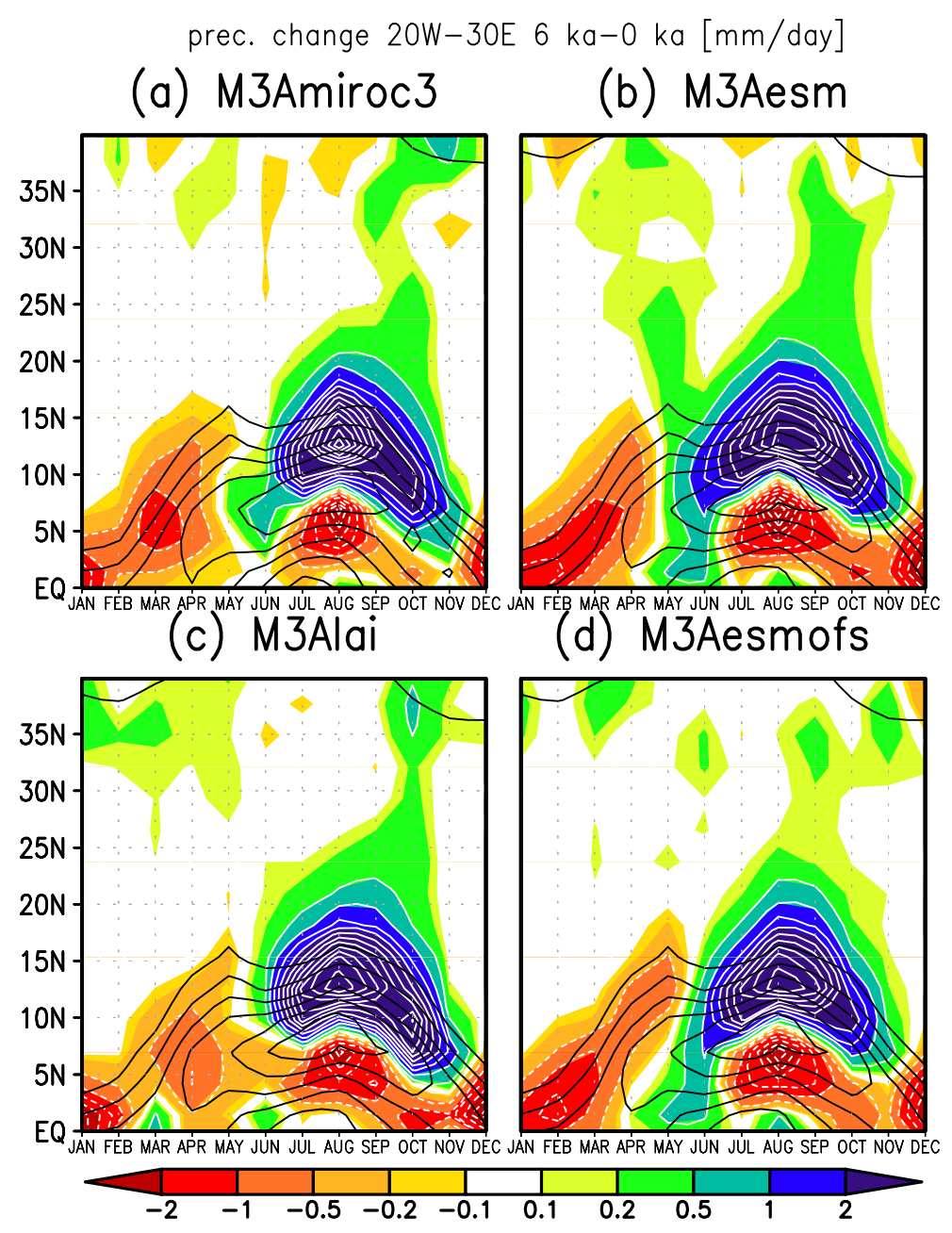

Fig. 15. Hovmöller diagrams of the precipitation change over northern Africa $\left(20^{\circ} \mathrm{W}-30^{\circ} \mathrm{E}\right)$ in the different sensitivity experiments using the AGCM of MIROC3 for (a) M3Amiroc3, (b) M3Aesm, (c) M3Alai and (d) M3Aesmofs, in the same format as Fig. 13a.

\subsubsection{Vegetation changes and feedback in MIROC-ESM}

The LAI calculated in SEIB-DGVM is supplied to MATSIRO within MIROC-ESM. To further investigate the mechanism of vegetation change and feedback on the climate at $6 \mathrm{ka}$ in MIROC-ESM simulations, we performed a set of sensitivity experiments, M3Alai, for 0 and $6 \mathrm{ka}$ (Table 3 ) using the AGCM of MIROC3. The experiments are the same as those with M3Amiroc3 except that we use the LAIs obtained for the 0 and $6 \mathrm{ka}$ simulations using MIROC-ESM. The resulting $6 \mathrm{ka}$ precipitation changes over northern Africa are compared with M3Amiroc3 results in Fig. 15a and c. There is a statistically similar level of enhanced precipitation for M3Amiroc3 and M3Alai throughout the year, as seen from the $95 \%$ confidence interval in a $t$ test. This indicates that the different LAI simulated in SEIB-DGVM has little effect on the 6 ka precipitation change over the Sahara.

The difference between the 6-0 ka temperature changes in M3Alai and M3Amiroc3 suggest that the LAI feedback has a warming effect over high latitudes and a cooling effect mainly over desert (not shown). The mid/high-latitude amplification of the warming at $6 \mathrm{ka}$ by vegetation feedback is consistent with the results of O'ishi and Abe-Ouchi (2011), who handled the vegetation coupling on MIROC using another dynamic vegetation scheme and suggested that the increased vegetation at the mid-high latitudes can lead to lower albedo during summer, indirect amplification through sea ice feedback in autumn and winter and snow albedo feedback in spring. The cooling during JJAS seen over North America suggests that the vegetation feedback suppresses warming over the area at $6 \mathrm{ka}$, which may explain the difference between the results of MIROC-ESM and MIROC3 in Fig. 3. 


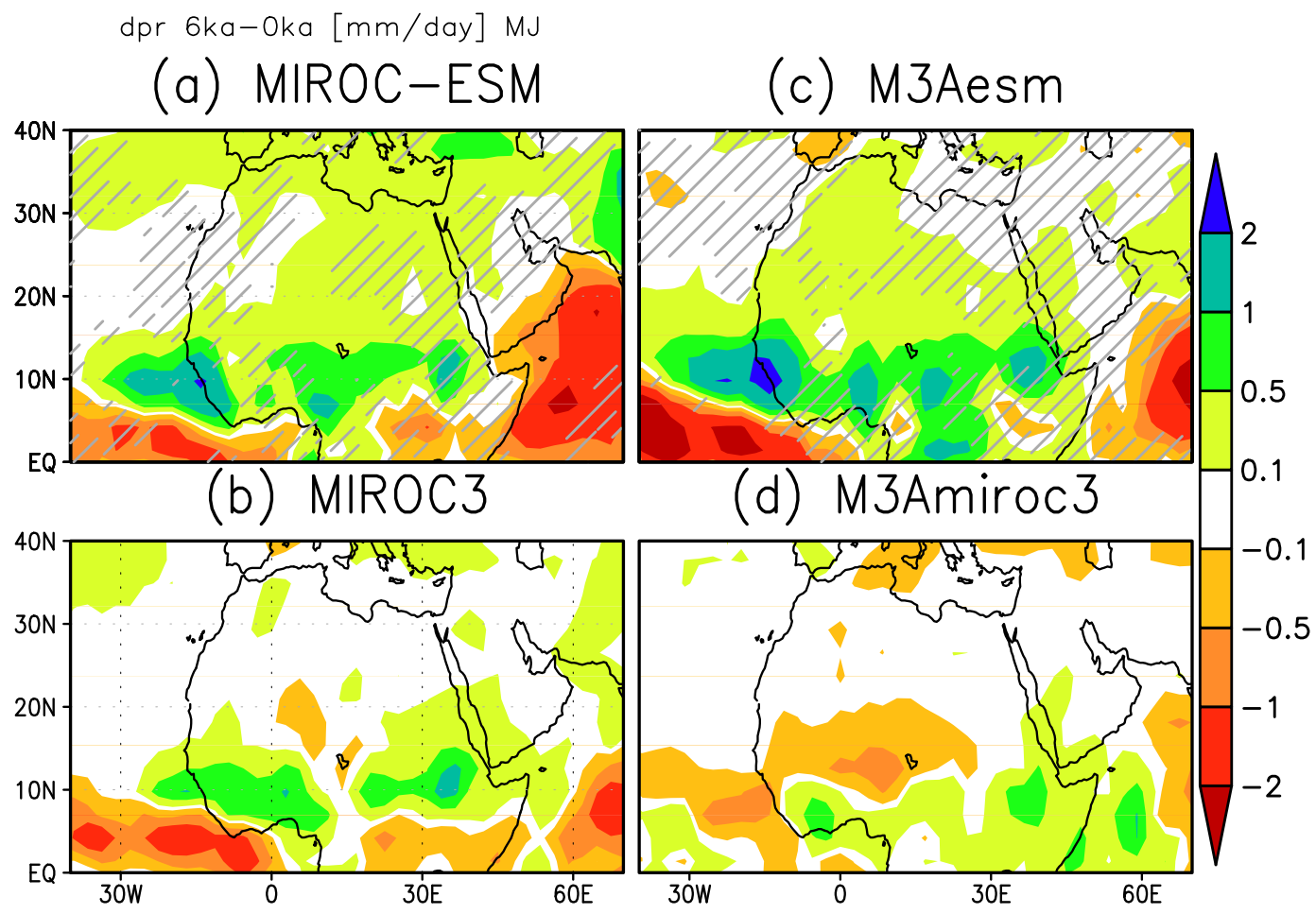

Fig. 16. 6- 0 ka precipitation change over the African area in MJ (mm day ${ }^{-1}$ ) for (a) MIROC-ESM, (b) MIROC3, (c) M3Aesm, and (d) M3Amiroc3. Hatched areas in the upper figures indicate regions where the precipitation changes in the upper and lower panels are insignificant in a $t$ test $(95 \%)$.

\section{Summary and discussion}

We have given an overview of $6 \mathrm{ka}$ time-slice experimental results from the Earth System Model, MIROC-ESM in a comparison with those from a previous version of the MIROC AOGCM, namely MIROC3. One model might outperform the other in some aspects of the representation of climate change. However, there is still worth in comparing these two similar models, as we know which components they have in common. Analysis of the differences in climate change obtained with the two models allows an investigation into the sources of differences in climate change simulations and also into the abilities and limitations of the models.

The physics of MIROC-ESM and MIROC3 comprise of different atmosphere and land processes. Since MIROCESM includes a full carbon cycle, it is capable of calculating atmospheric $\mathrm{CO}_{2}$. However, following the CMIP5/PMIP3 protocol, the calculated $\mathrm{CO}_{2}$ level is not passed back to the physics component in the experiments using MIROC-ESM.

For $6 \mathrm{ka}$, the two models simulate changes which were generally consistent with one another. SSTs obtained with the models are slightly lower over the tropics. Compared to $0 \mathrm{ka}$, the air temperature is higher at mid/high latitudes in the Northern Hemisphere, mainly over the continents during the boreal summer, but lower during the boreal winter. Both models simulate slightly lower net temperature changes at
$6 \mathrm{ka}$ but MIROC-ESM simulates a temperature drop larger than that in MIROC3. This is due to differences in the atmosphere (for example, the representation of low-level clouds) and/or vegetation components of the two models. Although the difference is too small to judge which model simulates a change more consistent with that suggested by the proxy records, the North Atlantic SST cooling in MIROC-ESM is different to those from the PMIP2 models (Braconnot et al., 2007).

The precipitation shifts northward and is enhanced over the area of the northern Africa and the Asian monsoons mainly in JJAS. The northward extension of the precipitation enhancement over northern Africa at $6 \mathrm{ka}$, as seen in MIROC-ESM, does not differ greatly from that obtained with MIROC3. We thus conclude that newly developed components such as the dynamic vegetation and improvements in the atmospheric processes do not have any significant impacts on the representation of the $6 \mathrm{ka}$ monsoon change suggested by proxy records. This is also confirmed by the MPI scheme.

According to the sensitivity experiments using the AGCM of MIROC3, at $6 \mathrm{ka}$, the small precipitation enhancement seen during early summer over the Sahara in MIROC-ESM, but not in MIROC3, could be related to the difference between the SST changes in the two models and/or the representation of the precipitation at $0 \mathrm{ka}$ and/or SST rather than 
(a) MIROC-ESM Oka

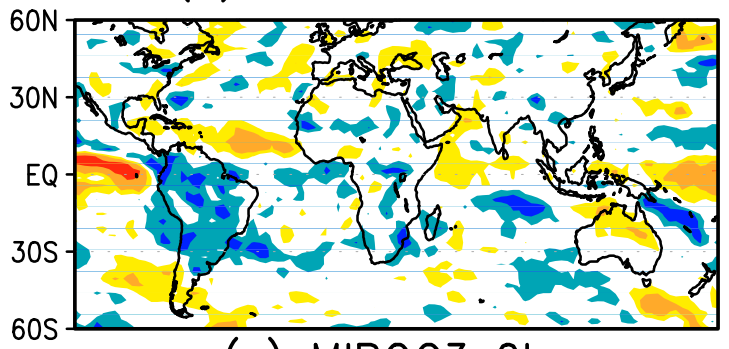

(c) MIROC3 Oka

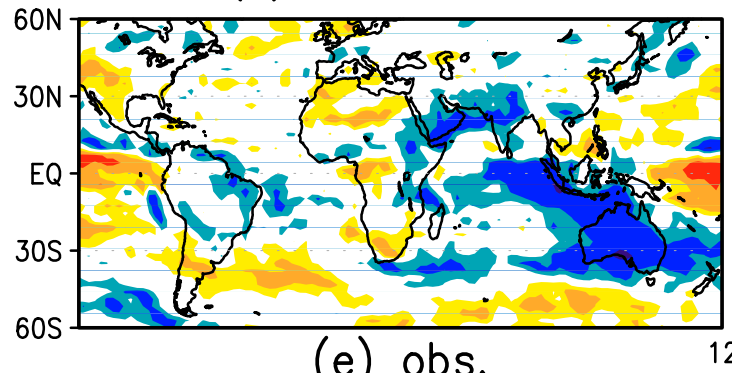

(e) obs.

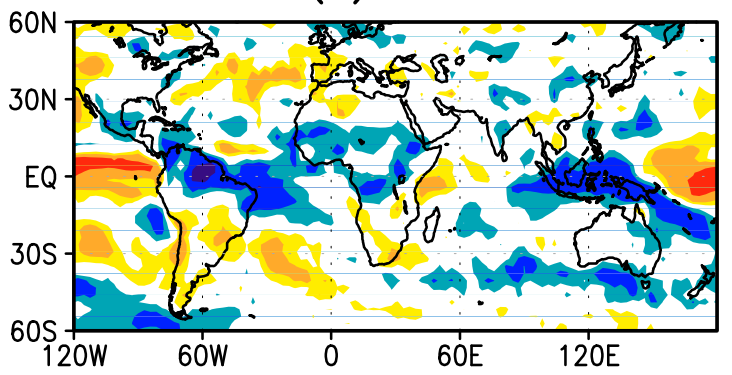

(b) MIROC-ESM $6 \mathrm{ka}$

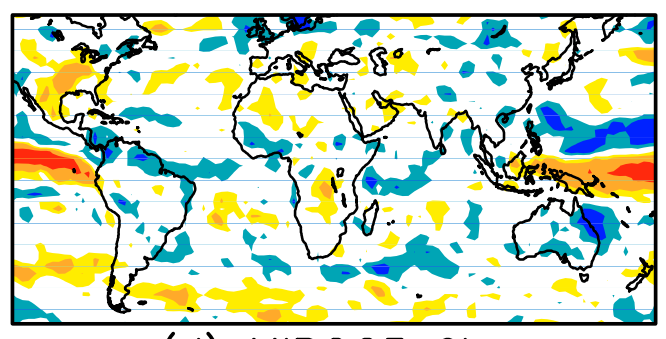

(d) MIROC3 6ka

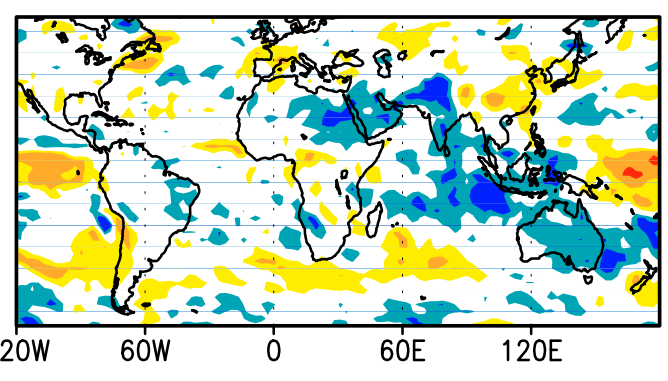

JJAS Nino3-prec correlation

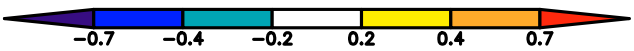

Fig. 17. Correlation coefficients of Niño3-precipitation in JJAS for $0 \mathrm{ka}$ (left panels) and $6 \mathrm{ka}$ (right panels) obtained with MIROC-ESM (upper panels) and MIROC3 (middle panels) taken from 28 arbitrary years within the analysis periods. (e) The correlation coefficients calculated from GPCP data set and Hadley Centre's sea ice and sea surface temperature data set (Rayner et al., 2003) from 1979 to 2006 AD.

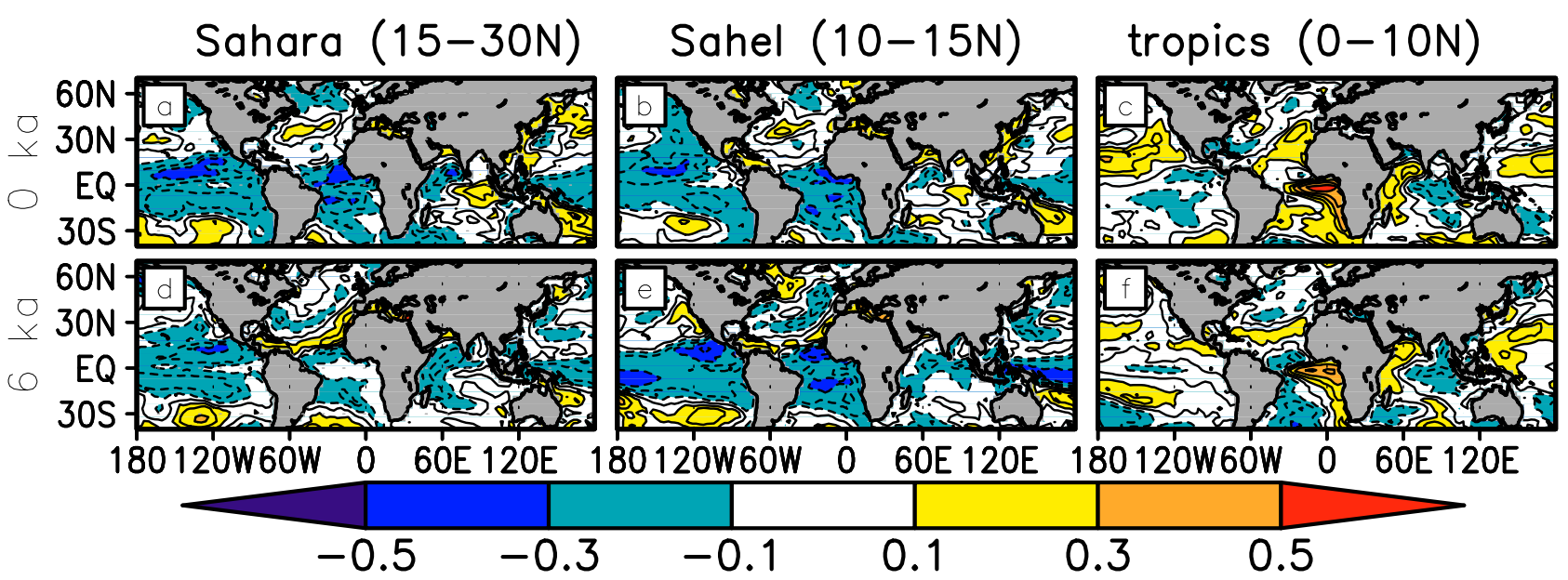

Fig. 18. Correlations between precipitation over different latitudes of the northern African $\left(20^{\circ} \mathrm{W}-30^{\circ} \mathrm{E}\right)$ area and SSTs in JJAS for 0 and $6 \mathrm{ka}$ obtained with MIROC-ESM for $0 \mathrm{ka}(\mathbf{a}, \mathbf{b}, \mathbf{c})$ and $6 \mathrm{ka}(\mathbf{d}, \mathbf{e}, \mathbf{f})$. 
the vegetation feedback in MIROC-ESM. The influence of the $0 \mathrm{ka}$ SST representation had been pointed out for precipitation enhancement in the Asian monsoon region at $6 \mathrm{ka}$ by Ohgaito and Abe-Ouchi (2009). The slight difference in the 0 ka SST representation may also affect the 6 ka precipitation change over Africa. Both models simulate precipitation enhancement which is insufficient to maintain vegetation over the Sahara, as was the case in previous studies using models of various complexities, as described in Sect. 1.

The correlation between the oceanic variability and the African precipitation are also investigated. The correlation between ENSO and precipitation is weak in the two MIROC models. But the weak representation of ENSO at $0 \mathrm{ka}$ in both models may affect the results. The correlation between North African precipitation and SST was also investigated. No strong correlation is seen at either 0 or $6 \mathrm{ka}$ for the Sahel/Sahara area. But the correlations with the nearby ocean tend to be more positive at $6 \mathrm{ka}$.

Although the most frequent vegetation types simulated by SEIB-DGVM in MIROC-ESM reveal a northward shift of vegetation of only one or two grids in the Sahel area at $6 \mathrm{ka}$ compared to $0 \mathrm{ka}$, there are far fewer permanent desert grid points over the Sahara region. Such sporadic vegetation might be evidenced in pollen proxy records.

The effect of vegetation coupling is small in our experiments. However, it is possible that the method of coupling SEIB-DGVM to MATSIRO through LAI change affects the results of climate change simulations in the situation where vegetation types differ significantly from those of presentday, such as in the case of the Sahara at $6 \mathrm{ka}$. This should be addressed in future model development. Improvements in not only the vegetation module, but also in the convective cloud scheme, for example, may play a role in precipitation intrusion towards the Sahara at $6 \mathrm{ka}$ (Chikira et al., 2006).

It should be noted that despite the continual development of climate models, the representation of climate at $0 \mathrm{ka}$ will always contain flaws to some extent. Although MIROC, as state-of-the-art models, represent the 0 ka climate reasonably well, further improvements in areas such as the climatological and/or variability of SST simulation in MIROC-ESM and other models will allow for more robust climate change simulations. Although our experiments focus on only one time period from the past, what has been suggested could also be valid for future climate projections using the same kind of models.

In addition, it should be noted that the sensitivity experiments have limitations because they use experimental settings of lower complexity and ignore the year to year variability of the ocean and/or vegetation. It is not known if there is any synergetic effect on the precipitation from the airsea-land interaction. In order to study this further, we would need to perform sensitivity experiments such as those using MIROC-ESM with inactivated vegetation feedback, and this is left for future work.
Acknowledgements. We are grateful for the constructive comments and suggestions by M. Notaro, G. Ramstein and an anonymous reviewer. We appreciate the discussions on the land processes with R. O'ishi. We thank W.-L. Chan and J. D. Annan for editorial help. NODC_WOA98 data provided by the NOAA/OAR/ESRL PSD, Boulder, Colorado, USA, from their Web site at http://www.esrl.noaa.gov/psd/. This work was conducted partly under the Program for Risk Information on Climate Change supported by Ministry of Education, Culture, Sports, Science and Technology - Japan (MEXT). The simulations in this study were conducted on Earth Simulator.

Edited by: G. Ramstein

\section{References}

Adler, R. F., Huffman, G. J., Chang, A., Ferraro, R., Xie, P., Janowiak, J., Rudolf, B., Schneider, U., Curtis, S., Bolvin, D., Gruber, A., Susskind, J., and Arkin, P.: The Version 2 Global Precipitation Climatology Project (GPCP) Monthly Precipitation Analysis (1979-Present), J. Hydrometeorol., 4, 1147-1167, 2003.

Bader, J. and Latif, M.: The impact of decadal-scale Indian Ocean sea surface temperature anomalies on Sahelian rainfall and the North Atlantic Oscillation. Geophys. Res. Lett., 30, 2169-2172, 2003.

Bartlein, P. J., Harrison, S. P., Brewer, S., Connor, S., Davis, B. A. S., Gajewski, K., Guiot, J., Harrison-Prentice, T. I., Henderson, A., Peyron, O., Prentice, I. C., Scholze, M., Seppa, H., Shuman, B., Sugita, S., Thompson, R. S., Viau, A. E., Williams, J., and $\mathrm{Wu}, \mathrm{H}$.: Pollen-based continental climate reconstructions at 6 and 21 ka: a global synthesis. Clim. Dynam., 37, 775-802, 2011.

Bergengren, J. C., Thompson, S. L., Pollard, D., and DeConto, R. M.: Modeling global climate-vegetation interactions in a doubled $\mathrm{CO}_{2}$ world, Climatic Change, 50, 31-75, 2001.

Berger A.: Long-term variations of daily insolation and Quaternary climatic changes, J. Atmos. Sci., 35, 2362-2367, 1978.

Biasutti, M., Held, I. M., Sobel, A. H., and Giannini, A.: SST forcings and Sahel rainfall variability in simulations of the twentieth and twenty-first centuries, J. Climate, 21, 3471-3486, 2008.

Bigelow, N. H., Brubaker, L. B., Edwards, M. E., Harrison, S. P., Prentice, I. C., Anderson, P. M., Andreev, A. A., Bartlein, P. J., Christensen, T. R., Cramer, W., Kaplan, J. O., Lozhkin, A. V., Matveyeva, N. V., Murray, D. F., Mcguire, A. D., Razzhivin, V. Y., Ritchie, J. C., Smith, B., Walker, D. A., Gajewski, K., Wolf, V., Holmqvist, B. H., Igarashi, Y., Kremenetskii, K., Paus, A., Pisaric, M. F. J., and Volkova, V. S.: Climate change and Arctic ecosystems: 1 . Vegetation changes north of 55 degrees $\mathrm{N}$ between the last glacial maximum, mid-Holocene, and present, J. Geophys. Res.-Atmos., 108, 8170-8194, 2003.

Braconnot, P., Joussaume, S., Marti, O., and De Noblet, N.: Synergistic feedbacks from ocean and vegetation on the African monsoon response to mid-Holocene insolation, Geophys. Res. Lett., 26, 2481-2484, 1999.

Braconnot, P., Joussaume, S., De Noblet, N., and Ramstein, G.: Mid-holocene and Last Glacial Maximum African monsoon changes as simulated within the Paleoclimate Modelling Intercomparison Project, Global Planet. Change, 26, 51-66, 2000. 
Braconnot, P., Otto-Bliesner, B., Harrison, S., Joussaume, S., Peterchmitt, J.-Y., Abe-Ouchi, A., Crucifix, M., Driesschaert, E., Fichefet, Th., Hewitt, C. D., Kageyama, M., Kitoh, A., Laîné, A., Loutre, M.-F., Marti, O., Merkel, U., Ramstein, G., Valdes, P., Weber, S. L., Yu, Y., and Zhao, Y.: Results of PMIP2 coupled simulations of the Mid-Holocene and Last Glacial Maximum Part 1: experiments and large-scale features, Clim. Past, 3, 261277, doi:10.5194/cp-3-261-2007, 2007.

Braconnot, P., Harrison, S. P., Kageyama, M., Bartlein, P. J., Masson-Dermotte, V., Abe-Ouchi, A., Otto-Bliesner, B., and Zhao, Y.: Evaluation of climate models using palaeoclimatic data, Nature Climate Change, 2, 417-424, doi:10.1038/nclimate1456, 2012.

Brostrom, A., Coe, M., Harrison, S. P., Gallimore, R., Kutzbach, J. E., Foley, J., Prentice, I. C., and Behling, P.: Land surface feedbacks and palaeomonsoons in northern Africa, Geophys. Res. Lett., 25, 3615-3618, 1998.

Brown, J., Collins, M., Tudhope, A. W., and Toniazzo, T.: Modelling mid-Holocene tropical climate and ENSO variability: towards constraining predictions of future change with palaeodata, Clim. Dynam., 30, 19-36, 2008.

Charney, J. G.: Dynamics of deserts and drought in sahel, Q. J. Roy. Meteorol. Soc., 101, 193-202, 1975.

Chikira, M., Abe-Ouchi, A., and Sumi, A.: General circulation model study on the green Sahara during the mid-Holocene: An impact of convection originating above boundary layer, J. Geophys. Res.-Atmos., 111, 21103-21121, 2006.

Claussen, M. and Gayler, V: The greening of the Sahara during the mid-Holocene: results of an interactive atmosphere-biome model, Global Ecol. Biogeogr., 6, 369-377, 1997.

Dallmeyer, A., Claussen, M., and Otto, J.: Contribution of oceanic and vegetation feedbacks to Holocene climate change in monsoonal Asia, Clim. Past, 6, 195-218, doi:10.5194/cp-6-1952010, 2010.

Doherty, R., Kutzbach, J., Foley, J., and Pollard, D.: Fully coupled climate/dynamical vegetation model simulations over Northern Africa during the mid-Holocene, Clim. Dynam., 16, 561-573, 2000.

Douville, H., Chauvin, F., and Broqua, H.: Influence of soil moisture on the Asian and African monsoons, Part I: Mean monsoon and daily precipitation, J. Climate, 14, 2381-2403, 2001.

Douville, H., Conil, S., Tyteca, S., and Voldoire, A.: Soil moisture memory and West African monsoon predictability: artefact or reality?, Clim. Dynam., 28, 723-742, 2007.

Fontaine, B., Garcia-Serrano, J., Roucou, P., Rodriguez-Fonseca, B., Losada, T., Chauvin, F., Gervois, S., Sijikumar, S., Ruti, P., and Janicot, S.: Impacts of warm and cold situations in the Mediterranean basins on the West African monsoon: observed connection patterns (1979-2006) and climate simulations, Clim. Dynam., 35, 95-114, 2010.

Gagan, M. K., Hendy, E. J., Haberle, S. G., and Hantoro, W. S.: Post-glacial evolution of the indo-pacific warm pool and el ninosouthern oscillation, Quatern. Int., 118, 127-143, 2004.

Ganopolski, A., Kubatzki, C., Claussen, M., Brovkin, V., and Petoukhov, V.: The influence of vegetation-atmosphere-ocean interaction on climate during the mid-Holocene, Science, 280, 1916-1919, 1998.

Hall, N. M. J. and Valdes, P. J.: A gcm simulation of the climate 6000 years ago, J. Climate, 10, 3-17, 1997.
Harrison, S. P., Yu, G., Takahara, H., and Prentice, I. C.: Palaeovegetation - Diversity of temperate plants in east Asia, Nature, 413, 129-130, 2001.

Harrison, S. P., Kutzbach, J. E., Liu, Z., Bartlein, P. J., OttoBliesner, B., Muhs, D., Prentice, I. C., and Thompson, R. S.: Mid-Holocene climates of the Americas: a dynamical response to changed seasonality, Clim. Dynam., 20, 663-688, 2003.

Hewitt, C. D. and Mitchell, J. F. B.: A fully coupled GCM simulation of the climate of the mid-Holocene, Geophys. Res. Lett., 25, 361-364, 1998.

Hurrell, J. W., Hack, J. J., Shea, D., Caron, J. M., and Rosinski, J.: A new sea surface temperature and sea ice boundary dataset for the Community Atmosphere Model, J. Climate, 21, 5145-5153, 2008.

Jones, P. D., New, M., Parker, D. E., Martin, S., and Rigor, I. G.: Surface air temperature and its changes over the past 150 years, Rev. Geophys., 37, 173-199, 1999.

Joussaume, S., Taylor, K. E., Braconnot, P., Mitchell, J. F. B., Kutzbach, J. E., Harrison, S. P., Prentice, I. C., Broccoli, A. J., Abe-Ouchi, A., Bartlein, P. J., Bonfils, C., Dong, B., Guiot, J., Herterich, K., Hewitt, C. D., Jolly, D., Kim, J. W., Kislov, A., Kitoh, A., Loutre, M. F., Masson, V., Mcavaney, B., Mcfarlane, N., De Noblet, N., Peltier, W. R., Peterschmitt, J. Y., Pollard, D., Rind, D., Royer, J. F., Schlesinger, M. E., Syktus, J., Thompson, S., Valdes, P., Vettoretti, G., Webb, R. S., and Wyputta, U.: Monsoon changes for 6000 years ago: Results of 18 simulations from the Paleoclimate Modeling Intercomparison Project (PMIP), Geophys. Res. Lett., 26, 859-862, 1999.

K-1 model developers: K-1 coupled model (MIROC) description, in: K-1 technical report 1, edited by: Hasumi, H. and Emori, S., Center for Climate System Research, University of Tokyo, 34 pp., 2004.

Kim, H. J., Takata, K., Wang, B., Watanabe, M., Kimoto, M., Yokohata, T., and Yasunari, T.: Global Monsoon, El Niño, and Their Interannual Linkage Simulated by MIROC5 and the CMIP3 CGCMs, J. Climate, 24, 5604-5618, 2011.

Knorr, W. and Schnitzler, K. G.: Enhanced albedo feedback in North Africa from possible combined vegetation and soil-formation processes, Clim. Dynam., 26, 55-63, 2006.

Kohfeld, K. E. and Harrison, S. P.: How well can we simulate past climates? Evaluating the models using global palaeoenvironmental datasets, Quaternary Sci. Rev., 19, 321-346, 2000.

Kutzbach, J. E., Bartlein, P. J., Foley, J. A., Harrison, S. P., Hostetler, S. W., Liu, Z., Prentice, I. C., and Webb, T.: Potential role of vegetation feedback in the climate sensitivity of high-latitude regions: A case study at 6000 years BP, Global Biogeochem. Cy., 10, 727-736, 1996a.

Kutzbach, J., Bonan, G., Foley, J., and Harrison, S. P.: Vegetation and soil feedbacks on the response of the African monsoon to orbital forcing in the early to middle Holocene, Nature, 384, 623626, $1996 \mathrm{~b}$.

Levis, S., Bonan, G. B., and Bonfils, C.: Soil feedback drives the mid-Holocene North African monsoon northward in fully coupled CCSM2 simulations with a dynamic vegetation model, Clim. Dynam., 23, 791-802, 2004.

Lezine, A. M., Hely, C., Grenier, C., Braconnot, P., and Krinner, G.: Sahara and Sahel vulnerability to climate changes, lessons from Holocene hydrological data, Quaternary Sci. Rev., 30, 30013012, 2011. 
Liu, Z., Gallimore, R. G., Kutzbach, J. E., Xu, W., Golubev, Y., Behling, P., and Selin, R.: Modeling long-term climate changes with equilibrium asynchronous coupling, Clim. Dynam., 15, 325-340, 1999.

Liu, Z., Otto-Bliesner, B., Kutzbach, J., Li, L., and Shields, C.: Coupled climate simulation of the evolution of global monsoons in the Holocene, J. Climate, 16, 2472-2490, 2003.

Liu, Z., Harrison, S. P., Kutzbach, J., and Otto-Bliesner, B.: Global monsoons in the mid-Holocene and oceanic feedback, Clim. Dynam., 22, 157-182, 2004.

Liu, Z., Notaro, M., and Gallimore, R.: Indirect vegetation-soil moisture feedback with application to Holocene North Africa climate, Global Change Biol., 16, 1733-1743, 2010.

Liu, Z. Y., Kutzbach, J., and Wu, L. X.: Modeling climate shift of El Nino variability in the Holocene, Geophys. Res. Lett., 27, 22652268, 2000.

Losada, T., Rodriguez-Fonseca, B., Janicot, S., Gervois, S., Chauvin, F. and Ruti, P.: A multi-model approach to the Atlantic Equatorial mode: impact on the West African monsoon, Clim. Dynam., 35, 29-43, 2010a.

Losada, T., Rodriguez-Fonseca, B., Polo, I., Janicot, S., Gervois, S., Chauvin, F., and Ruti, P.: Tropical response to the Atlantic Equatorial mode: AGCM multimodel approach. Clim. Dynam., 35, 45-52, 2010b.

Marzin, C. and Braconnot, P.: The role of the ocean feedback on Asian and African monsoon variations at $6 \mathrm{kyr}$ and $9.5 \mathrm{kyr} \mathrm{BP}, \mathrm{C}$. R. Geosci., 341, 643-655, 2009a.

Marzin, C. and Braconnot, P.: Variations of Indian and African monsoons induced by insolation changes at 6 and $9.5 \mathrm{kyr} \mathrm{BP}$, Clim. Dynam., 33, 215-231, 2009b.

Masson, V. and Joussaume, S.: Energetics of the 6000-yr bp atmospheric circulation in boreal summer, from large-scale to monsoon areas: A study with two versions of the lmd agcm, J. Climate, 10, 2888-2903, 1997.

McGregor, H. V. and Gagan, M. K.: Western Pacific coral_180 records of anomalous Holocene variability in the El NirnoSouthern Oscillation, Geophys. Res. Lett., 31, L11204, doi:10.1029/2004GL019972, 2004.

Mohino, E., Rodriguez-Fonseca, B., Mechoso, C. R., Gervois, S., Ruti, P., and Chauvin, F.: Impacts of the Tropical Pacific/Indian Oceans on the Seasonal Cycle of the West African Monsoon, J. Climate, 24, 3878-3891, 2011.

Notaro, M., Wang, Y., Liu, Z., Gallimore, R., and Levis, S.: Combined statistical and dynamical assessment of simulated vegetation-rainfall during the mid-Holocene, Global Change Biol., 14, 347-368, 2008.

Notaro, M., Chen, G., and Liu, Z.: Vegetation feedbacks to climate in the global monsoon regions, J. Climate, 24, 5740-5756, 2011.

Ohgaito, R. and Abe-Ouchi, A.: The role of ocean thermodynamics and dynamics in Asian summer monsoon changes during the mid-Holocene, Clim. Dynam., 29, 39-50, 2007.

Ohgaito, R. and Abe-Ouchi, A.: The effect of sea surface temperature bias in the PMIP2 AOGCMs on mid-Holocene Asian monsoon enhancement, Clim. Dynam., 33, 975-983, 2009.

O'ishi, R. and Abe-Ouchi, A.: Polar amplification in the midHolocene derived from dynamical vegetation change with a GCM, Geophys. Res. Lett., 38, 14702-14707, 2011.
Otto, J., Raddatz, T., Claussen, M., Brovkin, V., and Gayler, V.: Separation of atmosphere-ocean-vegetation feedbacks and synergies for mid-Holocene climate, Geophys. Res. Lett., 36, 0970109705, 2009.

Philippon, N., Mougin, E., Jarlan, L., and Frison, P. L.: Analysis of the linkages between rainfall and land surface conditions in the West African monsoon through CMAP, ERS-WSC, and NOAA-AVHRR data, J. Geophys. Res.-Atmos., 110, 24115 24128, 2005.

Pickett, E. J., Harrison, S. P., Hope, G., Harle, K., Dodson, J. R., Kershaw, A. P., Prentice, I. C., Backhouse, J., Colhoun, E. A., D'costa, D., Flenley, J., Grindrod, J., Haberle, S., Hassell, C., Kenyon, C., Macphail, M., Martin, H., Martin, A. H., Mckenzie, M., Newsome, J. C., Penny, D., Powell, J., Raine, J. I., Southern, W., Stevenson, J., Sutra, J. P., Thomas, I., Van Der Kaars, S., and Ward, J.: Pollen-based reconstructions of biome distributions for Australia, Southeast Asia and the Pacific (SEAPAC region) at 0, 6000 and 18,000 ${ }^{14}$ C yr BP, J. Biogeogr., 31, 1381-1444, 2004.

Prentice, I. C., Jolly, D., and Participants, B.: Mid-Holocene and glacial-maximum vegetation geography of the northern continents and Africa, J. Biogeogr., 27, 507-519, 2000.

Rayner, N. A., Parker, D. E., Horton, E. B., Folland, C. K., Alexander, L. V., Rowell, D. P., Kent, E. C., and Kaplan, A.: Global analyses of sea surface temperature, sea ice, and night marine air temperature since the late nineteenth century, J. Geophys. Res.Atmos., 108, D144407, doi:10.1029/2002JD002670, 2003.

Rodbell, D. T., Seltzer, G. O., Anderson, D. M., Abbott, M. B., Enfield, D. B., and Newman, J. H.: An similar to 15,000-year record of El Nino-driven alluviation in southwestern Ecuador, Science, 283, 516-520, 1999.

Rodriguez-Fonseca, B., Janicot, S., Mohino, E., Losada, T., Bader, J., Caminade, C., Chauvin, F., Fontaine, B., Garcia-Serrano, J., Gervois, S., Joly, M., Polo, I., Ruti, P., Roucou, P., and Voldoire, A.: Interannual and decadal SST-forced responses of the West African monsoon, Atmos. Ssci. Lett., 12, 67-74, 2011.

Rodwell, M. J. and Hoskins, B. J.: Monsoons and the dynamics of deserts, Q. J. Roy. Meteorol. Soc., 122, 1385-1404, 1996.

Roxy, M., Gualdi, S., Drbohlav, H. K. L., and Navarra, A.: Seasonality in the relationship between El Nino and Indian Ocean dipole, Clim. Dynam., 37, 221-236, 2011.

Sato, H., Itoh, A., and Kohyama, T.: SEIB-DGVM: A new dynamic global vegetation model using a spatially explicit individualbased approach, Ecol. Model., 200, 279-307, 2007.

Sekiguchi, M. and Nakajima, T.: A k-distribution-based radiation code and its computational optimization for an atmospheric general circulation model, J. Quant. Spectrosc. Ra., 109, 2779-2793, 2008.

Smethie, W. M. and Fine, R. A.: Rates of north atlantic deep water formation calculated from chlorofluorocarbon inventories, DeepSea Res. Pt. I, 48, 189-215, 2001.

Sueyoshi, T., Ohgaito, R., Yamamoto, A., Chikamoto, M. O., Hajima, T., Okajima, H., Yoshimori, M., Abe, M., O'ishi, R., Saito, F., Watanabe, S., Kawamiya, M., and Abe-Ouchi, A.: Set-up of the PMIP3 paleoclimate experiments conducted using an Earth system model, MIROC-ESM, Geosci. Model Dev., 6, 819-836, doi:10.5194/gmd-6-819-2013, 2013. 
Takemura, T., Okamoto, H., Maruyama, Y., Numaguti, A., Higurashi, A., and Nakajima, T.: Global three-dimensional simulation of aerosol optical thickness distribution of various origins, J. Geophys. Res.-Atmos., 105, 17853-17873, 2000.

Takemura, T., Nakajima, T., Dubovik, O., Holben, B. N., and Kinne, S.: Single-scattering albedo and radiative forcing of various aerosol species with a global three-dimensional model, J. Climate, 15, 333-352, 2002.

Takemura, T., Nozawa, T., Emori, S., Nakajima, T. Y., and Nakajima, T.: Simulation of climate response to aerosol direct and indirect effects with aerosol transport-radiation model. J. Geophys. Res.-Atmos., 110, 02202-02217, 2005.

Talley, L. D., Reid, J. L., and Robbins, P. E.: Data-based meridional overturning streamfunctions for the global ocean, J. Climate, 16, 3213-3226, 2003.

Taylor, K. E., Stouffer, R. J., and Meehl, G. A.: A summary of the CMIP5 experimental design, available at: http://cmip-pcmdi.llnl. gov/cmip5/docs/Taylor_CMIP5_design.pdf (last access: 22 January 2011), 2009.

Texier, D., De Noblet, N., Harrison, S. P., Haxeltine, A., Jolly, D., Joussaume, S., Laarif, F., Prentice, I. C., and Tarasov, P.: Quantifying the role of biosphere-atmosphere feedbacks in climate change: coupled model simulations for 6000 years BP and comparison with palaeodata for northern Eurasia and northern Africa, Clim. Dynam., 13, 865-882, 1997.

Tudhope, A. W., Chilcott, C. P., McCulloch, M. T., Cook, E. R., Chappell, J., Ellam, R. M., Lea, D. W., Lough, J. M., and Shimmield, G. B.: Variability in the El-Niño Southern Oscillation Through a Glacial-interglacial Cycle, Science, 291, 1511-1517, 2001.

Vamborg, F. S. E., Brovkin, V., and Claussen, M.: The effect of a dynamic background albedo scheme on Sahel/Sahara precipitation during the mid-Holocene, Clim. Past, 7, 117-131, doi:10.5194/cp-7-117-2011, 2011

Vettoretti, G., Peltier, W. R., and Mcfarlane, N. A.: Simulations of mid-holocene climate using an atmospheric general circulation model, J. Climate, 11, 2607-2627, 1998.

Vizy, E. K. and Cook, K. H.: Mechanisms by which Gulf of Guinea and eastern North Atlantic sea surface temperature anomalies can influence African rainfall, J. Climate, 14, 795-821, 2001.

Voss, R. and Mikolajewicz, U.: The climate of 6000 years BP in near-equilibrium simulations with a coupled AOGCM, Geophys. Res. Lett., 28, 2213-2216, 2001.

Wang, B., Kim, H. J., Kikuchi, K., and Kitoh, A.: Diagnostic metrics for evaluation of annual and diurnal cycles, Clim. Dynam., 37, 941-955, 2011.

Wang, B., Liu, J., Kim, H.-J., Webster, P. J., and Yim, S.-Y.: Recent change of the global monsoon precipitation (1979-2008), Clim. Dynam., 39, 1123-1135, 2012.
Wang, Y., Notaro, M., Liu, Z., Gallimore, R., Levis, S., and Kutzbach, J. E.: Detecting vegetation-precipitation feedbacks in mid-Holocene North Africa from two climate models, Clim. Past, 4, 59-67, doi:10.5194/cp-4-59-2008, 2008.

Watanabe, S., Hajima, T., Sudo, K., Nagashima, T., Takemura, T., Okajima, H., Nozawa, T., Kawase, H., Abe, M., Yokohata, T., Ise, T., Sato, H., Kato, E., Takata, K., Emori, S., and Kawamiya, M.: MIROC-ESM 2010: model description and basic results of CMIP5-20c3m experiments, Geosci. Model Dev., 4, 845-872, doi:10.5194/gmd-4-845-2011, 2011.

Wohlfahrt, J., Harrison, S. P., Braconnot, P., Hewitt, C. D., Kitoh, A., Mikolajewicz, U., Otto-Bliesner, B. L., and Weber, S. L.: Evaluation of coupled ocean-atmosphere simulations of the midHolocene using palaeovegetation data from the northern hemisphere extratropics, Clim. Dynam., 31, 871-890, 2008.

World Ocean Atlas: Tech. rep., National Oceanographic Data Center, http://www.esrl.noaa.gov/psd/, Version 2, Silver Spring, Maryland, 1998.

Xue, Y. K., Juang, H. M. H., Li, W. P., Prince, S., Defries, R., Jiao, Y., and Vasic, R.: Role of land surface processes in monsoon development: East Asia and West Africa, J. Geophys. Res.-Atmos., 109, 03105-03128, 2004.

Yu, G., Chen, X., Ni, J., Cheddadi, R., Guiot, J., Han, H., Harrison, S. P., Huang, C., Ke, M., Kong, Z., Li, S., Li, W., Liew, P., Liu, G., Liu, J., Liu, Q., Liu, K. B., Prentice, I. C., Qui, W., Ren, G., Song, C., Sugita, S., Sun, X., Tang, L., Vancampo, E., Xia, Y., Xu, Q., Yan, S., Yang, X., Zhao, J., and Zheng, Z.: Palaeovegetation of China: a pollen data-based synthesis for the mid-Holocene and last glacial maximum, J. Biogeogr., 27, 635-664, 2000.

Zeng, N., Neelin, J. D., Lau, K. M., and Tucker, C. J.: Enhancement of interdecadal climate variability in the Sahel by vegetation interaction, Science, 286, 1537-1540, 1999.

Zhao, Y. and Harrison, S. P.: Mid-holocene monsoons: A multimodel analysis of the inter-hemispheric differences in the responses to orbital forcing and ocean feedbacks, Clim. Dynam., 39, 1457-1487, 2012.

Zhao, Y., Braconnot, P., Marti, O., Harrison, S. P., Hewitt, C., Kitoh, A., Liu, Z., Mikolajewicz, U., Otto-Bliesner, B., and Weber, S. L.: A multi-model analysis of the role of the ocean on the African and Indian monsoon during the mid-Holocene, Clim. Dynam., 25, 777-800, 2005.

Zhao, Y., Braconnot, P., Harrison, S. P., Yiou, P., and Marti, O.: Simulated changes in the relationship between tropical ocean temperatures and the western African monsoon during the midHolocene, Clim. Dynam., 28, 533-551, 2007. 